\title{
Arctic rapid sea ice loss events in regional coupled climate scenario experiments
}

\author{
R. Döscher and T. Koenigk \\ SMHI/Rossby Centre Folkborgsvägen 17, 60176 Norrköping, Sweden \\ Correspondence to: R. Döscher (ralf.doescher@smhi.se) \\ Received: 29 May 2012 - Published in Ocean Sci. Discuss.: 9 July 2012 \\ Revised: 12 February 2013 - Accepted: 12 February 2013 - Published: 5 March 2013
}

\begin{abstract}
Rapid sea ice loss events (RILEs) in a miniensemble of regional Arctic coupled climate model scenario experiments are analyzed. Mechanisms of sudden ice loss are strongly related to atmospheric circulation conditions and preconditioning by sea ice thinning during the seasons and years before the event. Clustering of events in time suggests a strong control by large-scale atmospheric circulation. Anomalous atmospheric circulation is providing warm air anomalies of up to $5 \mathrm{~K}$ and is forcing ice flow, affecting winter ice growth. Even without a seasonal preconditioning during winter, ice drop events can be initiated by anomalous inflow of warm air during summer. It is shown that RILEs can be generated based on atmospheric circulation changes as a major driving force without major competing mechanisms, other than occasional longwave effects during spring and summer. Other anomalous seasonal radiative forcing or short-lived forcers (e.g., soot) play minor roles or no role at all in our model. RILEs initiated by ocean forcing do not occur in the model, although cannot be ruled out due to model limitations. Mechanisms found are qualitatively in line with observations of the 2007 RILE.
\end{abstract}

\section{Introduction}

The observed development of Arctic sea ice extent since the start of satellite observations in 1979 shows a long-term trend towards less ice, superimposed by interannual variability. For the annual summer minimum during September, new recent record minimum values have been observed during 2002, 2005, 2007 and 2012. By 2007, the average September extent trend since 1979 was $0.072 \times 10^{6} \mathrm{~km}^{2}$ per year (Stroeve et al., 2008 ). The 2007 event marked an unprecedented ice extent loss in the observed history downwards from $5.55 \times 10^{6} \mathrm{~km}^{2}$ in September 2005 to $4.28 \times 10^{6} \mathrm{~km}^{2}$ in September 2007. September 2012 showed an even stronger minimum of $3.41 \times 10^{6} \mathrm{~km}^{2}$.

Existing analyses of the observed 2007 event cover preconditioning, dynamic and radiative atmospheric forcing and mechanisms leading to increased bottom melting. There is a broad agreement on a multi-year trend of ice thinning and a low perennial ice coverage in previous years, which sets the stage for unusual, but not unprecedented atmospheric conditions to generate the 2007 event. The March 2007 sea ice extent and area were among the lowest three ever observed since the start of satellite observations in 1979 (Comiso et al., 2008).

During spring and early summer 2007, two surface pressure anomalies were established over the wider Arctic area. A sea level pressure (SLP) below normal over Siberia and the Laptev Sea was coinciding with positive conditions of the Northern Annular Mode (NAM) (Maslanik et al., 2007). Over the central Arctic and northern Canada, a high pressure anomaly occurred and persisted for three months. It was dominated by a strongly positive phase of the Pacific-North American (PNA) pattern (L'Heureux et al., 2008), a largescale wave pattern featuring a sequence of high- and lowpressure anomalies stretching from the subtropical west $\mathrm{Pa}$ cific to North America with a high pressure anomaly in the very north.

That specific combination of cyclonic and anticyclonic anomalies over the Arctic constitutes a dipole structure with meridional winds giving rise to advection of sea ice from the Pacific to the Atlantic sector of the Arctic accounting for about $15 \%$ of the total ice retreat in the Pacific sector (Kwok, 2008). Another effect was above-average air temperatures 
north of Siberia. The dipole pressure pattern had become more frequent in the winters and springs of the years before 2007, but persistence of this pattern through summer is unusual (Maslanik et al., 2007) and reasons for that persistence are unclear.

Associated with the anticyclonic (high pressure) anomaly over the western part of the Arctic, reduced cloudiness and enhanced down-welling radiation were found, which could have contributed to melting in the Pacific sector of the Arctic Ocean. Increased melting from the bottom of the sea ice in the Beaufort Sea was found by means of ice mass balance observations (Perovich et al., 2008). The primary source of heat was provided by solar radiation through increased fractions of open water. Additional solar heating due to a period of reduced cloud cover could have played a role. (Francis and Hunter 2006; Kay et al., 2008). That hypothesis was questioned by experiments with a coupled ocean-sea ice model (Schweiger et al., 2008) forced by a negative cloud anomaly and increased shortwave flux from June through August. No substantial contribution to the record sea ice extent minimum was found.

The overall picture of the 2007 event is diverse, and different possible specific mechanisms have been suggested, involving preconditioning, large-scale atmospheric variability, and local processes. Taking an integrated view based on a coupled ocean-sea ice simulation and using adjoint methods, Kauker et al. (2009) found that the 2007 summer sea ice event can be traced back to four major influences: the March sea ice thickness, May and June wind conditions favoring ice transport towards Fram Strait, and September surface air temperature.

Taking a broader view based on ensemble experiments with a coupled Arctic climate model, Dorn et al. (2012) confirm that the model's ability to reproduce observed summer sea ice retreat depends very much on "the correct simulation of the atmospheric circulation during the summer months and the sea-ice volume at the beginning of the melting period". Dorn et al. (2008) conclude that the thinning of the sea-ice cover as a background trend is a major reason for its increased response to variations in the atmospheric and oceanic circulations. However, the ice thinning on its own does not represent a sufficient condition for the occurrence of extremely low sea-ice extent.

Similar to the situation after earlier record sea ice minimum events, a partial recovery of the sea ice extent is observed after 2007. However, all summer extents after 2007 were below the 2005 value. Based on the previously observed record, it appears likely that new events could follow the 2007 event. This has already happened in 2012 during the revision phase of this paper. Therefore it is relevant to ask for the possible frequency of rapid change events and the range of possible underlying mechanisms and forcing situations. When it comes to probability and character of possible future Rapid sea ice loss events (RILEs), we need to consult numerical projections of future climates in the Arctic, re- sponding to increasing atmospheric greenhouse gas concentrations. Global climate models (GCMs) provide such scenario projections. By 2007, RILEs were rarely simulated in global climate simulations. Sea ice extent projections from several GCMs were compiled by the CMIP3 project (Zhang and Walsh, 2006). The amplitude of the observed 2007 event was far outside the variability of the GCM ensemble. Dissenting results in the CCSM GCM were given, e.g., by Holland et al. (2006), showing several ice loss events. Sea ice projections from the CMIP5 project were recently found to still underestimate the observed sea ice reduction, whereby a larger number of individual models, compared to CMIP3, simulate realistic ice extents and period-wise realistic trends (Massonet et al., 2012).

Regional dynamical downscaling of GCM scenario projections ("regional scenario") with a regional climate model (RCM) for the Arctic provides regional interpretation of global change with increased resolution. In this paper we present an analysis of several rapid sea ice loss events (RILEs), based on scenario downscaling experiments with a regional coupled climate model of the Arctic. Our Arctic regional scenario experiments show a level of overall sea ice extent in the Arctic Ocean for recent climate, which is close to real conditions (Koenigk et al., 2011). All our regional scenarios show rapid change events in summer sea ice extent. Those events consist of distinct drops in sea ice extent for one or more years in a row. After the event, a partial recovery is typically seen. Our analysis of RILEs aims at identifying relevant mechanisms for the drop and recovery of sea ice extent in a qualitative way. The benefit of doing this kind of analysis based on regional downscaled scenarios, instead of using the GCM directly, is seen in the stronger interannual variability of sea ice variables in the RCM compared to the GCM used for this study. The RCM's variability amplitude fits better to the observed RILEs during 2007 and 2012. Only few GCMs show RILEs (e.g., Holland et al., 2006)

Starting with descriptions of the regional model and the experimental setup, we describe spatially averaged time series of sea ice related fields and an average RILE. The role of the Arctic dipole anomaly pattern for the most extreme events is explored. Composites of the several events are presented to document the role of different mechanisms, and eventually three single events of varying character are analyzed. Conclusions are drawn regarding major mechanisms of preconditioning and ice loss.

\section{Model data and experiments}

To analyze rapid sea ice change events, we use six Arctic regional climate scenario experiments performed with the Rossby Centre Atmosphere Ocean model - RCAO (Döscher et al., 2002, 2010). All runs are performed as regional dynamic downscaling of global scenario projections by the Max Planck Institute climate model ECHAM5/MPI-OM (here: 
"the GCM") applying the A1B emission scenario as used for the CMIP3 project.

RCAO consists of the atmosphere component RCA and the ocean component RCO. The model area extends from about $50^{\circ} \mathrm{N}$ in the Atlantic sector across the Arctic to the Aleutian Island chain in the North Pacific as illustrated, e.g., in Fig 3. Both RCO and RCA run in a horizontal resolution of $0.5^{\circ}$ on a rotated latitude-longitude grid with the grid Equator crossing the geographical North Pole. The ocean component RCO has been described and verified for the Arctic (Döscher et al., 2010) and for a Baltic Sea domain (Meier et al., 2003). RCO comprises a dynamic-thermodynamic sea ice model based on an elastic-viscous-plastic (EVP) rheology (Hunke and Dukowicz, 1997) and a Semtner-type thermodynamics (Semtner, 1976). The ice and snow albedo formulation is based on a modified version of Køltzow (2007) with albedo values dependent on the ice surface temperature. A parameterization for melt ponds is included. RCO has 59 unevenly spaced vertical levels. A closed lateral boundary exists at the Aleutian Island chain and open lateral boundary conditions in the North Atlantic Ocean. In the case of inflowing water, climatologically monthly mean temperature and salinity data from the Polar Science Center Hydrographic Climatology (PHC) data set (Steele et al., 2001) or monthly ocean data from global scenario simulations of the Max Planck Institute climate model ECHAM5/MPIOM are used. Depending on the run, sea surface salinity is restored to the PHC climatology on a timescale of 240 days, or it is modified by a salinity flux correction (see Koenigk et al., 2011). This treatment is necessary to prevent artificial salinity drift due to insufficient provision of freshwater runoff and precipitation. This treatment is necessary to make model, forcing and climatological surface salinity compatible with each other (e.g., Gerdes and Köberle, 2007).

The atmosphere component RCA has been described by Jones et al. (2004a, b) and Kjellström et al. (2005). The current model setup has 24 vertical layers in terrain-following hybrid coordinates with a model top at approximately $15 \mathrm{hPa}$, where incoming solar radiation is the only forcing. As lateral boundary forcing, atmospheric data from ECHAM5/MPI$\mathrm{OM}$ are taken and updated with a 6-hourly frequency. Later improvements of RCA are described in Kjellström et al. (2005); Samuelsson et al. (2006) and Döscher et al. (2010). Both models RCO and RCA exchange information via a separate coupler software OASIS4 (Redler et al., 2009) with a coupling frequency of $3 \mathrm{~h}$.

The regional RCAO scenario experiments start 1 April 1960 and end 31 December 2080. All regional runs were initialized with GCM atmospheric fields and ocean temperature and salinity from the PHC climatology (Steele et al., 2001). Sea ice was initialized with a constant thickness of $2.3 \mathrm{~m}$ and a concentration of $95 \%$ for ocean grid boxes with a sea surface temperature (SST) colder than or equal to the freezing temperature. After $20 \mathrm{yr}$ of simulation between 1960 and 1979, the ocean fields are considered in advective quasi-equilibrium. As shown in Döscher et al. (2010), trend and mean values of sea ice extent after $20 \mathrm{yr}$ of integration are similar to observations during the 1980's and 1990s, when RCAO is forced with ERA-40 reanalysis at the lateral boundaries.

Our regional experiments use A1B scenario simulations of the last IPCC Assessment Report (IPCC, 2007) from the GCM ECHAM5/MPI-OM as forcing at the lateral boundaries. Radiative effects of the A1B greenhouse gas concentrations are prescribed even within the atmospheric component of RCAO.

Our six experiments (see Table 1) were initially designed as a sensitivity study and climate change projection experiment. The setup varies in forcing and sea ice parameters. Four out of our six experiments have been used for the climate change study of Koenigk et al. (2011). In some experiments, only the atmospheric fields of the global climate model (GCM) are used at the lateral boundaries, while the ocean boundaries are prescribed using climatological values. In addition, simulations have been performed with lateral forcing from both ocean and atmosphere of ECHAM5/MPI-OM. Certain runs utilize sea surface salinity restoring while others use salinity flux correction (see Koenigk et al., 2011). Different values for the freezing height of lateral freezing (see Döscher et al., 2010) are used to generate thinner or thicker sea ice conditions. All regional runs are forced by identical lateral atmosphere forcing from ECHAM5/MPI-OM. All runs utilize identical setups for the atmosphere component RCA.

\section{Definition of a rapid sea ice change event}

A rapid sea ice loss event (RILE) in this study is a quick and strong reduction of the annual minimum of sea ice extent during summer. In the Arctic, the minimum occurs during September. Here we define a RILE as a drop of summer sea ice extent by more than $1200000 \mathrm{~km}^{2}$ overall. The event can consist of one big drop ("one-step event") or of up to three consecutive steps of smaller year-to-year drops in a row ("multi-year event"). The first step is considered part of the event if it is larger than $500000 \mathrm{~km}^{2}$. Later on, the events are compared with average conditions of the respective 10-yr period directly before the start of the event. In the 6 regional scenario runs, we pick the first respective 5 events, which leaves us with a total of 30 events for analysis: 9 one-step events and 21 multi-year events.

\section{Results}

\subsection{Long-term trends and clustering of rapid ice loss events}

The coupled model's performance has been described in two previous papers (Döscher et al., 2010; Koenigk et al., 2011) 
Table 1. Scenario experiments. All runs are forced by identical atmosphere forcing from ECHAM5/MPI-OM. The term "thick-ice" refers to a sea ice configuration with thicker ice (see Döscher et al., 2010, their runs 210, 211, 112, 215). The term "std-ice" is a configuration with thinner ice. "SSS restoring" refers to a sea surface salinity restoring to climatological values (see Koenigk et al., 2011).

\begin{tabular}{ll}
\hline Experiment & Description \\
\hline ECH001 & Ocean: PHC winter climatology at Atlantic boundary, SSS restoring, std-ice \\
ECH002 & Ocean: PHC winter climatology at Atlantic boundary, SSS restoring, thick-ice \\
ECH003 & Ocean: PHC winter climatology at Atlantic boundary, surface salinity flux correction, std-ice \\
ECH004 & Ocean: PHC seasonal climatology at Atlantic boundary, SSS restoring, std-ice \\
ECH005 & Ocean: ECHAM5/MPI-OM at Atlantic boundary, SSS restoring, std-ice \\
ECH006 & Ocean: ECHAM5/MPI-OM at Atlantic boundary, surface salinity flux correction, std-ice \\
\hline
\end{tabular}
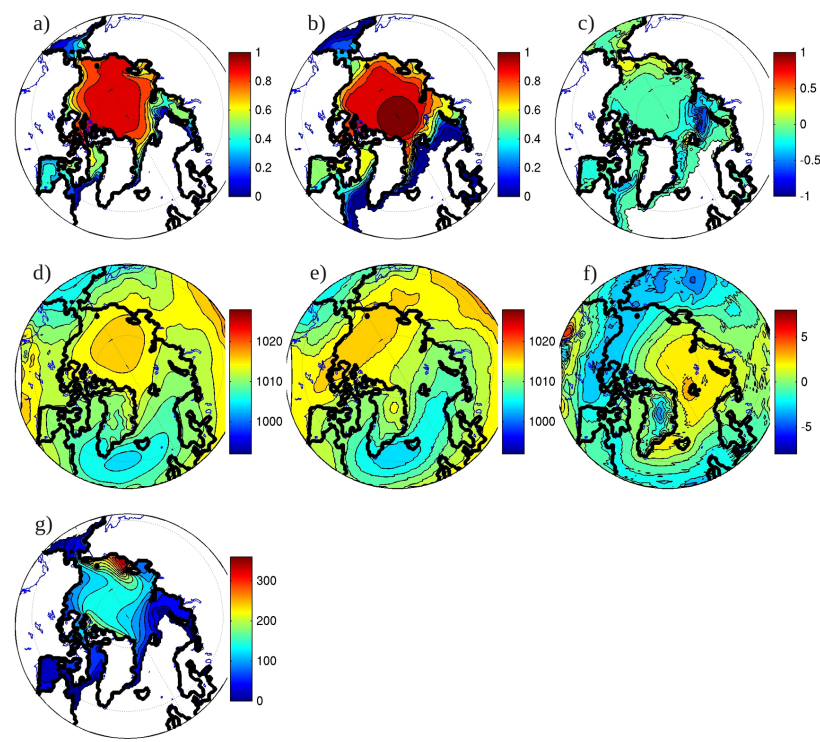

Fig. 1. Annual mean conditions 1980-2000 for the ensemble mean and observations. (a) Model sea ice concentration (SIC), (b) ERA40 sea ice concentration, (c) difference model SIC-ERA-40 SIC, (d) model SLP in hPa, (e) ERA-40 SLP, (f) difference model SLPERA-40 SLP, (g) model sea ice thickness in $\mathrm{cm}$.

including overall sea ice extent, volume and 2-m air temperature (T2M). Figure 1 shows 2-dimensional figures of sea ice concentration, thickness and SLP as annual means of the period 1980-2000 together with biases to better illustrate the underlying simulated recent climate. Ice concentration is overestimated in the Chukchi Sea and East Siberian Sea, and underestimated in the Barents and Kara Sea (Fig. 1c). A major limitation of the model is seen in sea ice thickness field (Fig. 1g) generally thinner than observed during recent climate. A comparison with observed climatology is not included here due to missing data. Local measurements and remote sensing show generally thicker ice in large parts of the Arctic Ocean, and thinner ice off eastern Siberia. Sea ice in the East Siberian Sea tends to be artificially thick as a result of insufficient treatment of ice classes (Mårtensson et al., 2012) and due to a high pressure bias over the Eurasian part of the Arctic Ocean (Fig. 1f), pressing ice from coasts of Greenland and Canada towards eastern Siberia. This problem is shared with several GCMs in similar ways (e.g., Chapman and Walsh, 2007; Vancoppenolle, 2008; Blanchard et al., 2011), and also regional climate models are affected, e.g., Arctic-WRF (Cassano et al., 2011).

The focus of this paper is on a description of processes with respect to rapid ice changes under the conditions and limitations given by this model, which includes sea ice generally thinner than recently observed and atmospheric temperatures warmer than today. The underlying model runs are scenario experiments not necessarily describing real future climates.

\subsection{Long-term trends and clustering of rapid ice loss events}

Spatial averages of seasonal means (JFM for winter and JAS for summer) for key variables have been calculated north of $70^{\circ} \mathrm{N}$ over the sea ice covered area with at least $15 \%$ of ice coverage (Fig. 2). In all ensemble runs overall trends are clearly visible. Over the 100-yr period 1980-2079, summer sea ice extent is decreasing (Fig. 2a), as is thickness (Fig. 2b) during summer and winter.

The increase of 2-m air temperature (T2M, Fig. 2d) is strongest during winter $(8-10 \mathrm{~K})$. Winter sea surface temperature (SST, Fig. 2c) change is much more limited (about $0.5 \mathrm{~K}$ ) due to the isolating ice cover and almost constant freezing point temperatures directly underneath the ice. Summer T2M and SST are increasing both with roughly $2-3 \mathrm{~K}$ (note different ordinate scaling in Fig. 2c and d) due to enlarged areas of leads and open water.

The strongest signals in melting rates are seen in the increasing summer melting at the ice bottom (Fig. 2e), which must be connected to water warming underneath the ice. A weaker increase is seen in the spring surface melting (no figure), while summer surface melting is decreasing. The latter is consistent with summer ice margins closer to the pole on average.

From the sea ice extent curve (Fig. 2a), it becomes clear that rapid loss events are followed by at least partial recoveries. This behavior is typical even for the observed sum- 


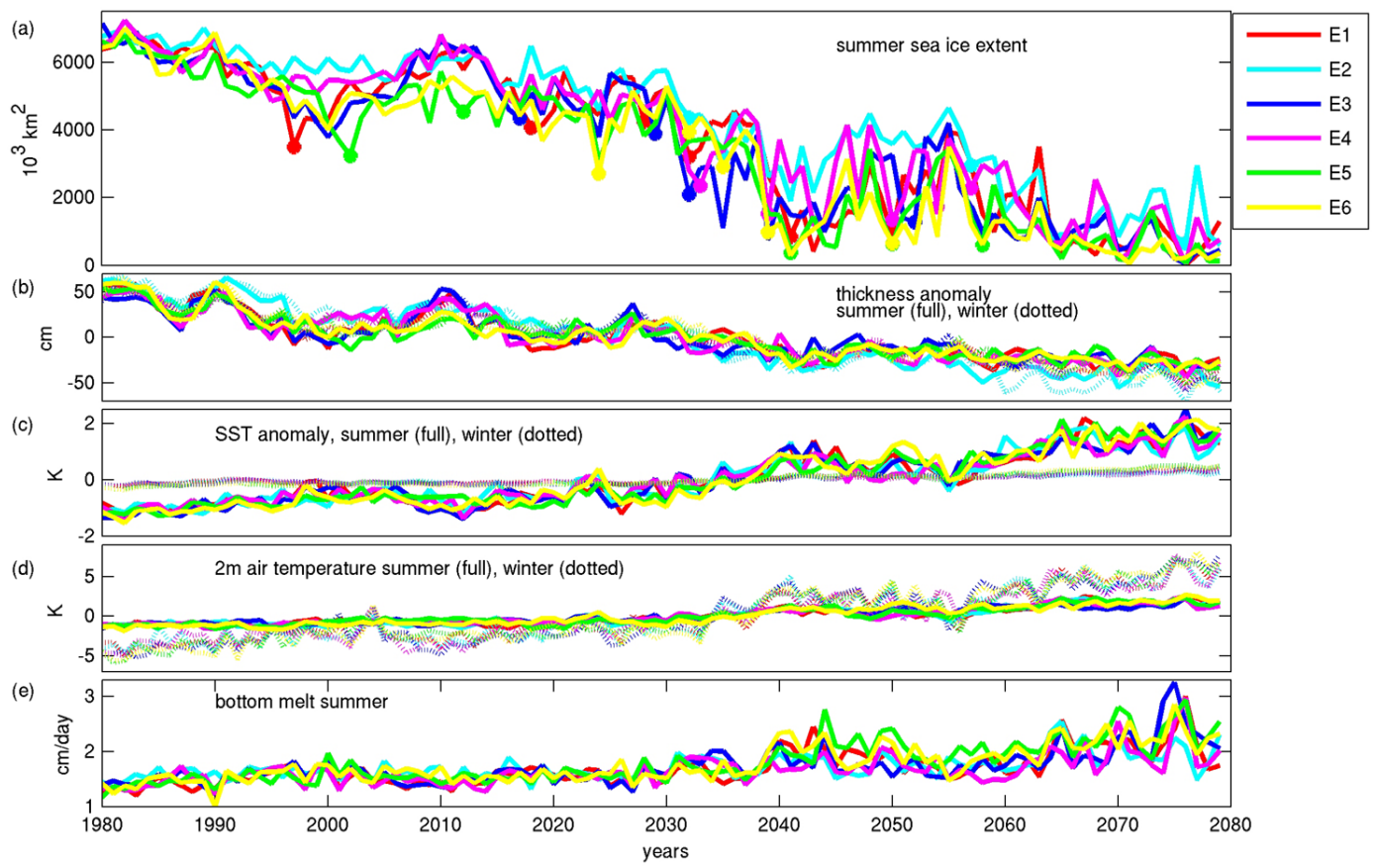

Fig. 2. Times series for six scenario experiments: (a) summer (JAS) sea ice extent in $10^{3} \mathrm{~km}^{2}$, (b) ice thickness anomaly in cm based on concentration-weighted annual minimum ("summer") and annual maximum ("winter") sea ice thickness, (c) spatially averaged summer SST anomaly north of $70^{\circ} \mathrm{N}$ in $\mathrm{K}$, (d) spatially averaged summer 2-m-atmospheric temperature anomaly north of $70^{\circ} \mathrm{N}$ in $\mathrm{K}$, (e) ice-area-averaged summer sea ice bottom melt rate in $\mathrm{cm} \mathrm{day}^{-1}$. Anomalies are given as deviations from the respective interannual seasonal mean over the complete time series.

mer extent time series (e.g., Stroeve et al., 2008). It opens for the possibility of negative feedbacks in response to the event. Alternatively, it might indicate that conditions suitable for generating a loss event exist only for a limited number of years before less favorable conditions reoccur independently of the ice loss.

Variability on top of the trends shows some intra-ensemble coherence on decadal scale and in some cases even on the annual scale. This is clearly visible, e.g., for sea ice extent, SST and T2M. While the long-term variability of extent is beyond our scope, we are interested in the sea ice loss events and their intra-ensemble coherence. Before 2025, ensemble members show largely individual behavior with respect to occurrence of a rapid loss events, although clustering of 23 ensemble members occurs. After 2025, events are mostly clustered within at least 4 ensemble members in periods of $3-5 \mathrm{yr}$, indicating that thin ice is more vulnerable to largescale atmospheric forcing. The coherence within the ensemble suggests some degree of controlling by large-scale conditions given by identical atmospheric conditions prescribed at the lateral boundaries of the regional model domain. Still, even after 2025, a minority of cases do not participate in the clustering of events. Thus conditions and processes specific to the individual ensemble runs are essential and can overrule a dominating large-scale influence emanating from identical lateral boundary conditions.
As an example of clustering, we take a closer look at the events during the period 2030-2035 to learn about preferred conditions for clustering. During that period, 5 out of $6 \mathrm{mem}-$ bers show a RILE, and the sixth member is close to an event. We compare the SLP of the event with a reference period of $10 \mathrm{yr}$ before the event (Fig. 3). We consider the average winter before an event and the average event summer itself. Both show a distinct high surface pressure anomaly over Alaska and northern Canada. During winter (Fig. 3a), the high anomaly is complemented by a pronounced negative anomaly covering most of the Arctic Ocean and centered over the Kara Sea reaching into northern Europe and Siberia. This indicates a broad anomalous inflow component from the Pacific Ocean into large parts of the central Arctic Ocean and towards the Canada and Greenland coast. In terms of total SLP (Fig. 3b and c), the SLP difference means reduced flow into the Chukchi and East Siberian Sea and stronger winds from the Laptev Sea towards northern Canada and Greenland during winter. During summer (Fig. 3d) increased pressure over North America and the Beaufort Sea implies a broader and stronger flow from the Chukchi Sea towards Barents Sea (Fig. 3e and f).

Both winter and summer conditions are connected to anomalous sea ice drift away from the Chukchi and East Siberian seas. Accordingly, both winter and summer sea ice thickness anomalies (Fig. 3g and $\mathrm{h}$ ) show strongest thinning 

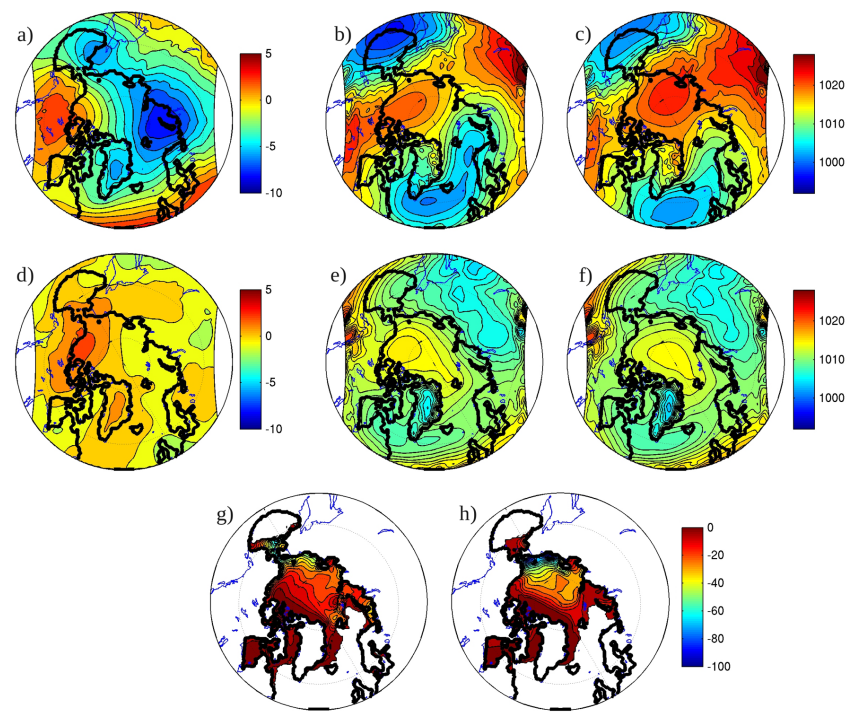

Fig. 3. Composite of RILEs during the period 2030-2035. Shown are SLP and SLP difference in hPa for composite winters (JFM) before the summer event and the composite event summers (JAS), as well as reference winters and summers as time-average over a reference period of $10 \mathrm{yr}$ before the respective events. (a) winter SLP difference, (b) winter SLP 2030-2035, (c) winter SLP for the reference period, (d) summer SLP difference, (e) summer SLP 20302035, (f) summer SLP for the reference period. Further: (g) composite sea ice thickness difference for the event year's winters and (h) for the event summers.

in the Chukchi Sea and East Siberian Sea and partly in the Laptev Sea.

Those are the conditions during a certain time period of strong large-scale control of sea ice loss events. The anomalies shown above explain the forcing mechanism of the events, but not why the mechanism is so powerful that all ensemble members actually generate an event at about the same time. Most of the 30 events do not show such a synchronicity. Compared with the overall 30-event average (Fig. 4), we find that the sea ice reduction during the clustering phase is very much concentrated on the Siberian coastal seas, while the 30-yr average shows reduction in almost all of the Arctic Ocean. We conclude that atmospheric conditions supporting ice loss in the Siberian coastal seas provide a strong constraint to generate a RILE. Most of our 30 events show some ice left at the East Siberian coast because of the thickness bias in that region (see Sect. 2). If this locally thick ice is counteracted by specific large-scale atmospheric conditions, such as given by this clustering event, we have a strong potential for common RILEs within the ensemble, largely independent of local conditions.

Taking into account that thick ice off Siberia is an unrealistic feature, given existing high pressure biases and the effects of not considering multiple ice classes, the described dominance of large-scale atmospheric conditions, only when counteracting that obstacle, is certainly unrealistic too. We speculate that a more realistic thickness distribution in combination with thin ice, without the obstacle, could lead to even more frequent clustering. This would be in line with the increased clustering after 2025, when the ice becomes comparatively thin.

\subsection{The average rapid sea ice loss event}

Sea ice rapid change events differ in the importance of specific mechanisms and the location of ice reduction. Analyzing an average event gives insights into dominating features valid for most events. More detailed understanding of processes needs to be derived from specific analysis such as composites (Sect. 4.5) and specific case studies (Sect. 4.6).

Here we present average seasonal anomaly fields over all 30 events. If an event consists of more than one step (i.e., several consecutive drops of summer extent in a row), all steps are taken into account and averaged into one average seasonal cycle of the event year. Each single anomaly field represents the difference between the respective season and the corresponding 10-yr seasonal mean before the start of the event. The average over all 30 events gives us anomalies for the seasons characterizing both an average RILE and an average recovery year after the event. Resulting fields are shown in Fig. 4a for the event and in Fig. 4b for the recovery. Melting rates for bottom and top of the ice are given in Fig. 4c.

The average winter (Fig. 4a, 1st column) before the average summer event shows a distinct T2M rise over all the Arctic Ocean and adjacent land areas, with a maximum warming of up to $2 \mathrm{~K}$ over the Chukchi Sea. That warming appears to be consistent with a winter SLP anomaly associated with anomalous warm air transport from the Pacific area into the Arctic. North-south gradients in actual SLP fields are weakened in most sectors, which implies an increased potential for north-south exchange.

Other winter anomalies are rather small: sea ice concentration (SIC) reduction is limited to the winter ice margin. Winter sea ice thickness (SIT) is reduced by up to $35 \mathrm{~cm}$ away from the northern Greenland and Canada coastal area. SST anomalies (no figure) reflect SIC changes. The SLP anomaly shows similarities with Fig. 3, which represents the conditions of efficient large-scale forcing of a RILE in the coming summer. A small but decisive difference is the weaker depression centered over the Kara Sea implying no direct ice drift from the East Siberian shelf towards Canada and Greenland.

It is interesting to note that the spatial pattern of the average T2M anomaly does not match average changes of SIC or SIT. Individual cases (such as considered in Sect. 4.6) show a coherence. The absence of such a spatial coherence in the average indicates either highly non-linear effects or the importance of anomalous advection of air from warmer areas.

During spring before the summer event (AMJ, Fig. 4a, 2nd column), T2M over the ice is still about $1 \mathrm{~K}$ warmer 


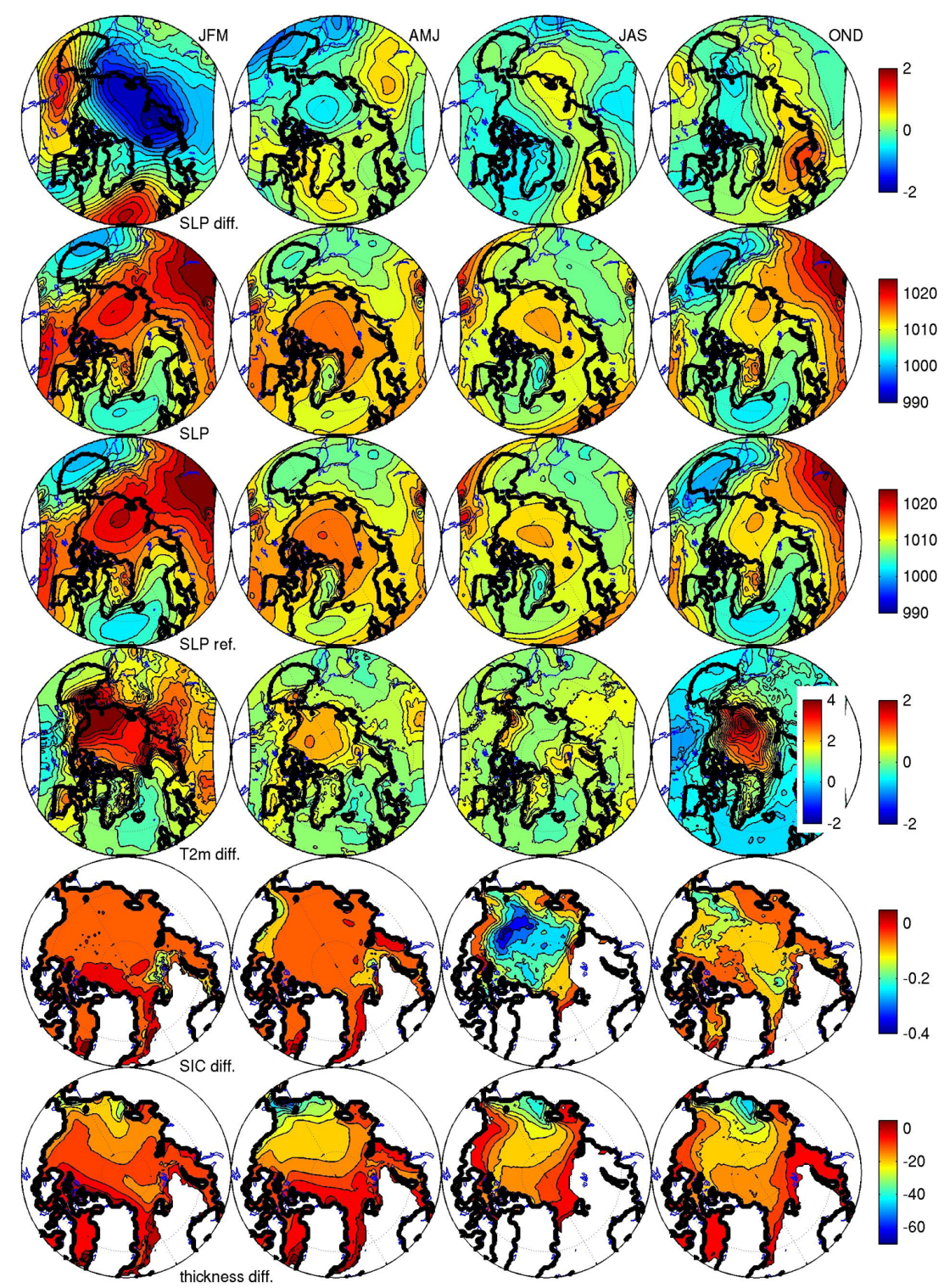

Fig. 4a. Seasonal conditions of the year of the rapid reduction event and average conditions of the 10-yr period before the event ("reference period"). Columns show the winter before the event (1st column), spring before the event (2nd column), summer of the event (3rd column), and fall after the event (4th column). "diff." denoted in the figure refers to difference between the season of the event year and the corresponding reference season. SIC difference and thickness difference are represented here as September mean instead of summer mean. Variables are SLP difference in hPa (1st row), SLP of the actual season (2nd row), SLP reference (3rd row), T2m difference in K (4th row), SIC difference (5th row) and sea ice thickness difference in $\mathrm{cm}$ (6th row). Black lines represent the ocean model coastlines and boundaries. Note the different color bar for fall 2-m air temperature during OND.

compared to the 10 -yr average before. That anomaly cannot be related to warm air advection as during winter, because SLP anomalies cannot support such an argument. Instead, we speculate that the T2M warming must be influenced by a reduced sea ice thickness as a result of the warm winter atmosphere. The SIT anomaly pattern is partly fitting the T2M anomaly. Thickness is reduced almost all over the ocean with values around $-30 \mathrm{~cm}$ in the central Arctic and maximum values of $-70 \mathrm{~cm}$. SIC is distinctly negative at the ice mar- gin of the Barents Sea and the Beaufort Sea coast, but only slightly negative away from the margins. Again, SST anomalies are roughly following the SIC.

During September (Fig. 4a, 3rd column), sea ice concentration (SIC) is reduced all over the place with maximum amplitudes of -0.4 in the central Arctic. This picture is the result of the 30-case-averaging procedure with individual cases occurring at different times during 100-yr-long model runs with generally retracting ice cover. Summer ice 


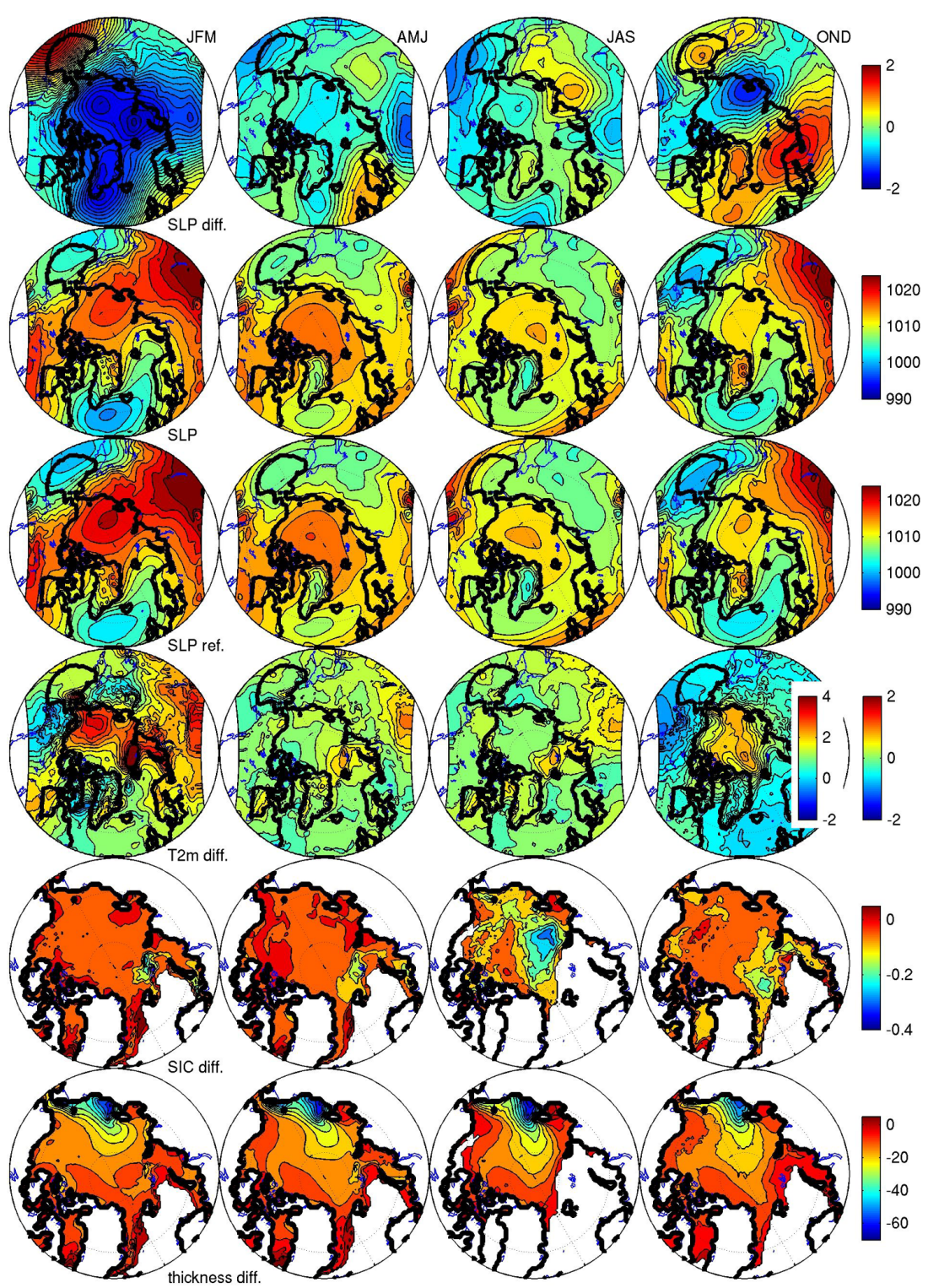

Fig. 4b. Seasonal conditions after the year of the rapid reduction event and average conditions of the 10-yr period before the event ("reference period"). Columns show the winter before the event (1st column), spring before the event ( 2 nd column), summer of the event ( 3 rd column), and fall after the event (4th column). "diff." denoted in the figure refers to difference between the season of the event year and the corresponding reference season. SIC difference and thickness difference are represented here as September mean instead of summer mean. Variables are SLP difference in hPa (1st row), SLP of the actual season (2nd row), SLP reference (3rd row), T2m difference in K (4th row), SIC difference (5th row) and sea ice thickness difference in $\mathrm{cm}$ (6th row). Black lines represent the ocean model coastlines and boundaries. Note the different color bar for fall 2-m air temperature during OND.

concentrations, averaged over the reference periods of the 30 cases, are small along the ice margins and thus limit the maximum ice concentration reduction in outer areas to smaller values than in the interior of the Arctic.

Atmospheric surface temperature (T2M) is only slightly increased during summer in ice margin areas (coastal Beaufort Sea and north of Spitsbergen), which are about consistent with a high number of ice-free summers among the 30 events in those areas. T2M also reflects reduced spring ice concentrations. Over the remaining ice, T2M is close to the freezing point.

The SLP anomaly during the summer event (Fig. 4a, 1st row) is given by an elongated high pressure ridge over the European and Eurasian coast, connected to an anomalous inflow of warm air from the Nordic seas into the Arctic Ocean. This is different from the externally controlled cases as illustrated in Fig. 3, indicating influence of internal processes rather than external control. The actual SLP fields (Fig. 4a 


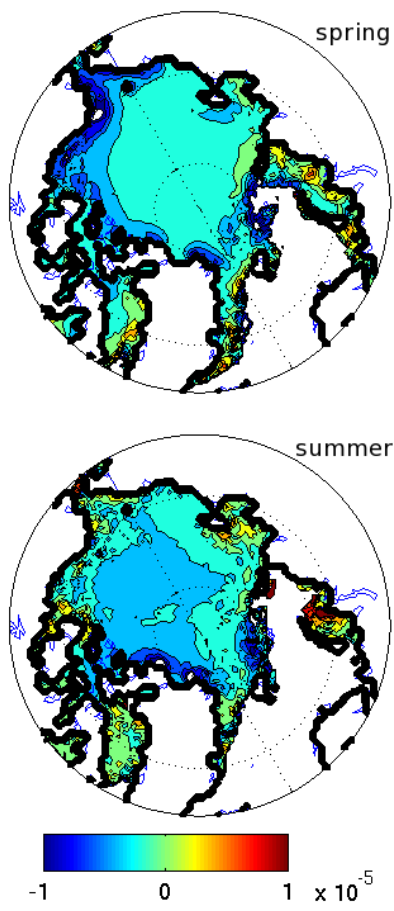

Fig. 4c. Bottom melting rate difference (in $\mathrm{cm} \mathrm{s}^{-1}$ ) between seasonal conditions of the year of the rapid reduction event and the average conditions of the 10-yr period before the event: spring (upper) and summer (lower, SIC). Negative values mean increased melting.

2nd and 3rd row) are showing minor differences only. The SLP anomaly pattern in stronger realization can be seen in individual cases (e.g., case \#16, Fig. 9a). In terms of absolute SLP change, it means a reduced atmospheric outflow from Barents Sea towards the Nordic seas and increased inflow from the Nordic seas into Fram Strait area (Sect. 4.6). Due to the averaging process, the SLP signal shown here is weak. Consequences of that average SLP anomaly on other average anomaly fields such as thickness or shape of ice cover cannot be detected here.

However, a similar SLP anomaly pattern is found in cases of rather moderate SIC reduction and in cases of moderate winter warming (no figure). Both cases are connected to smaller September loss events, indicating a role of this SLP anomaly pattern for modest loss events rather than for the most extreme events.

September sea ice thickness (in Fig. 4a, 5th row, 3rd column ) is reduced by up to $45 \mathrm{~cm}$. Areas of biggest average thinning are not completely identical with areas of strongest ice concentration reductions, indicating non-linearities due to different mechanisms involved in the individual events (thin ice can be highly concentrated or show large leads in different cases, such that the average does not reveal a relation), and due to very thick ice at parts of the Siberian coast.

Case studies (Sect. 4.6) and composite analysis (Sect. 4.5), which explore individual events or groups of events, both show a better coherence between reductions of thickness and concentration.

Bottom melting during spring and summer (Fig. 4c) is increased in large areas. Strongest melt rates are seen in those areas with strongest reduction of sea ice concentration. Increased heat absorption through leads affects water temperature underneath the ice, which in turn leads to stronger melting.

During fall (OND, Fig. 4a, 4th column), T2M over sea ice is much warmer (up to $3-4 \mathrm{~K}$ ) than during the reference period (the seasonal average over $10 \mathrm{yr}$ before). Anomalous atmospheric circulation slightly reduces southerly flow through Fram Strait. The clear limitation of the strongest warming pattern to the ocean strongly indicates that the much reduced SIC and a diminished ice thickness are the major reason for the warm air anomaly. Reduced ice concentration and thickness during the last three months of the year is consistent with the view of a delayed start of the freezing season with subsequently less dense and thinner ice cover. Similar effects have been observed after low-ice summers after year 2000 (Overland and Wang, 2010).

The average winter (JFM, Fig. 4b, 1st column) after a summer event still shows anomalously warm T2M over all the Arctic Ocean, but the signal is smaller and more localized than during the foregone fall. SIC is largely back to normal with slightly increased concentration in the Greenland Sea, indicating a recovery of sea ice extent above the 10-yr reference period. Ice thickness is still below normal away from the Nordic sea ice margins.

The T2M anomaly coincides partly with the negative SIC (between Svalbard and Severnaya Zemlya) and partly with with the thickness anomaly (Chukchi and East Siberian seas). In addition, The T2M warming is reminiscent of the foregone fall SIC anomaly pattern, indicating a possible signal storage in the ocean surface temperature, later converted to a thickness anomaly.

The SLP anomaly shows a low pressure anomaly over large parts of the Arctic and Nordic sea area. The pattern is reminiscent of the positive phase of the Arctic oscillation.

The following spring (AMJ, Fig. 4b, 2nd column) shows only minor anomalies for T2M and SLP. Sea ice thickness anomalies show thinner ice persisting at the Siberian coast and in the Arctic interior (the transpolar drift area) compared to the reference period. Thinning of more than $10 \mathrm{~cm}$ can be considered exceeding the long-term trend. The same is true for the following summer (JAS, Fig. 4b, 3rd column), which in addition shows a recovered SIC compared to the summer before. However, the summer SIC is locally lower than the 10 -yr reference period.

During the following fall (OND, Fig. 4a, 4th column), T2M over the Arctic Ocean is still anomalously warm over the ice, likely due to ice concentrations or ice thickness, which are still below normal in the Arctic interior. The average SLP anomalies do rather not support advective influences. 

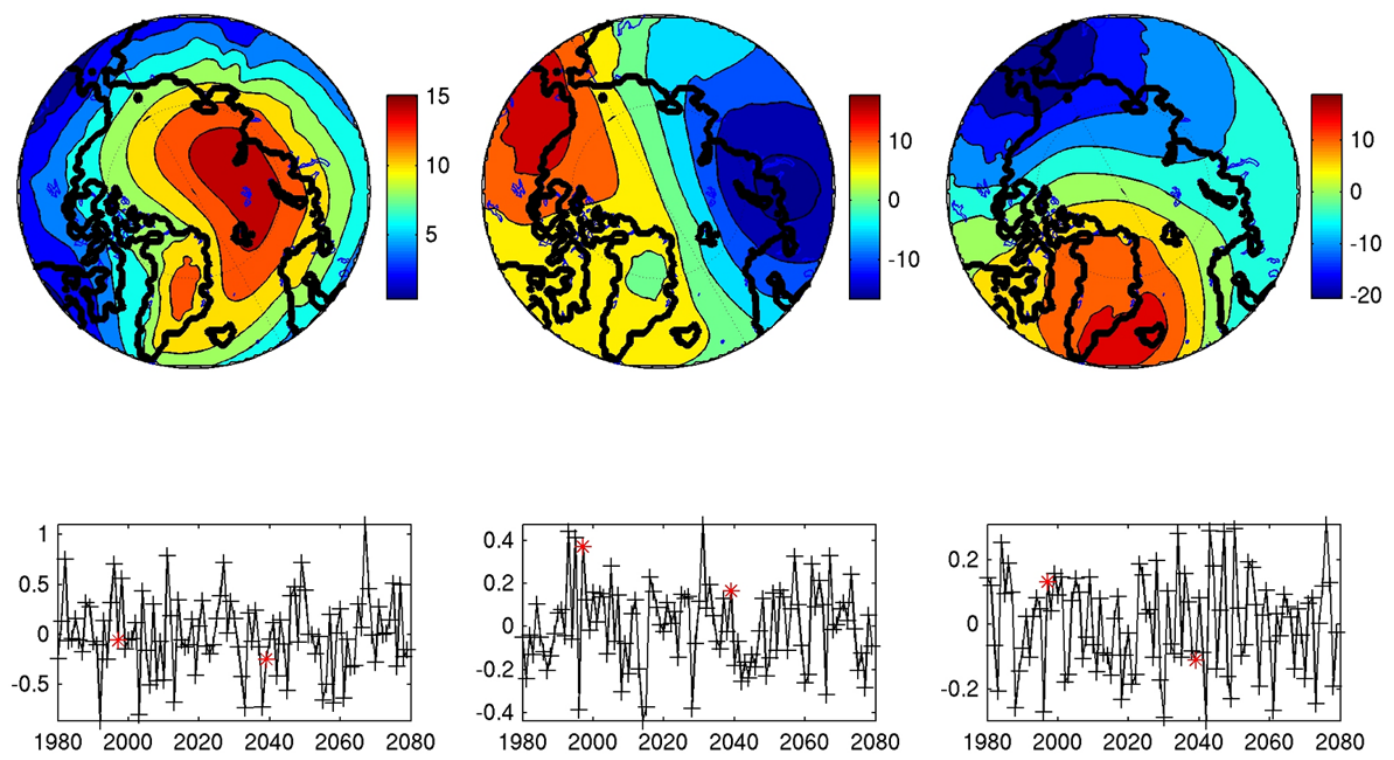

Fig. 5. EOF 1-3 of winter mean (JFM) sea level pressure in hPa (upper panel), PC (lower panel) for the scenario experiment E1. Red crosses indicate two out of the seven most extreme rapid sea ice reduction events.
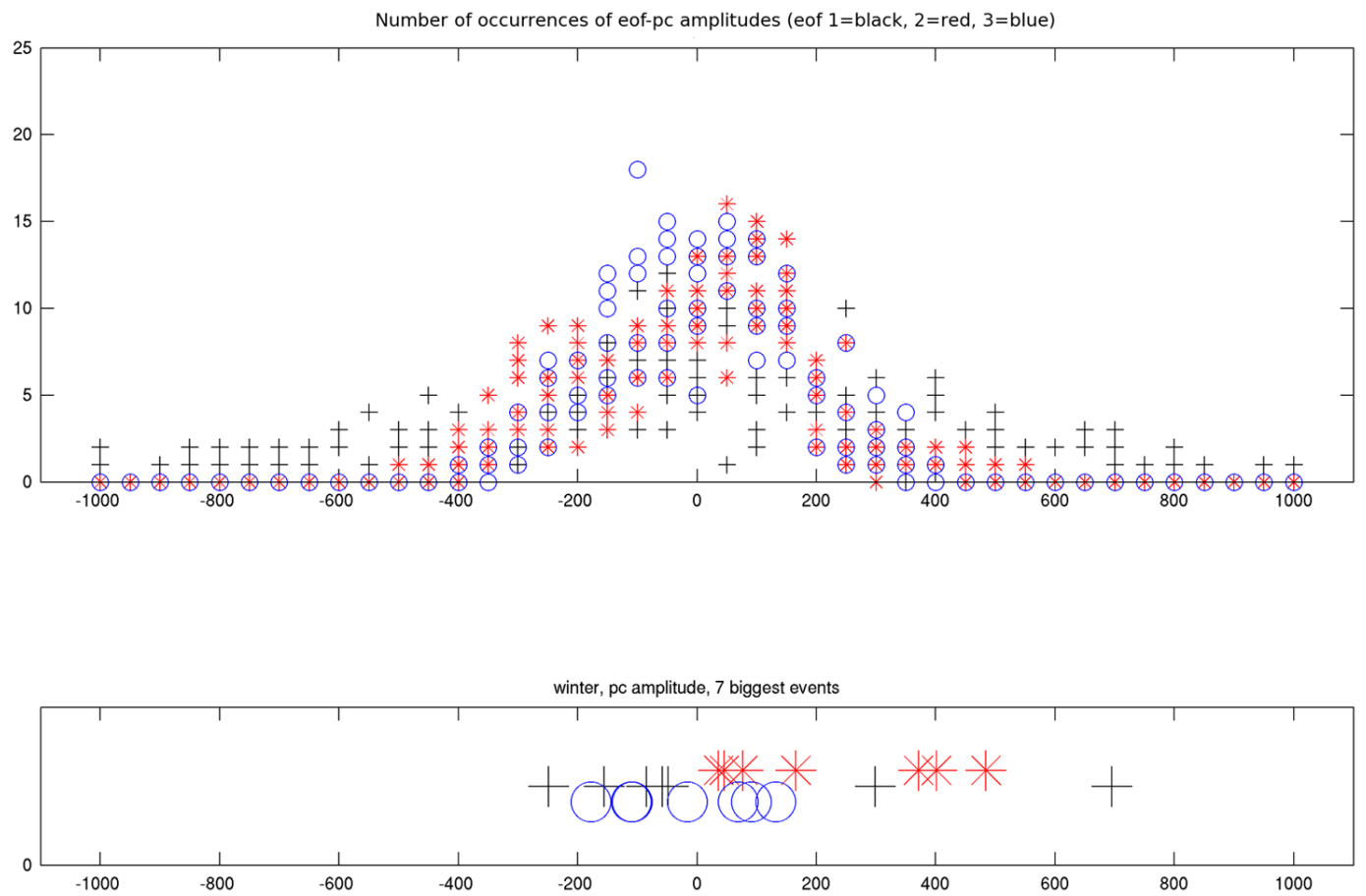

Fig. 6. Upper panel: Probability density function (PDF, number of occurrences) of winter (JFM) EOF-PC amplitudes (EOF1 = AO = black, $2=\mathrm{DA}=$ red, $3=$ blue) for all six scenario simulations. Lower panel: PC amplitudes of the first 3 EOFs for the 7 (out of 30 ) biggest rapid ice change events corresponding to the top $23 \%$ events.

Reviewing the average development of the ice field, we see only slightly reduced SIC during the average winter (JFM) of the event year. During the event summer, maximum reduction is reached. This is maintained even during the fall directly after the summer event. The following winter, spring and summer show only moderately negative SIC anomalies away from the ice margin. The interior ice thickness anomaly remains strongly negative during the complete 2 -yr period. Despite the only moderately negative SIC anomalies during the year after the event, we still find a strongly positive 
T2M anomaly during the second fall after the summer minimum event. Thus the T2M fall anomaly is reoccurring after a spring and a summer without relevant T2M anomalies, while the sea ice extent and concentration are clearly recovering. As the fall T2M anomaly is largely limited to the icecovered ocean area, its survival must be due to a signal storage mechanism related to sea ice or ocean. In the winter after the event, we see effects of a warmer ocean underneath the ice. For the year after the summer minimum, Blanchard et al. (2011) suggest a re-occurrence by means of memory in the ice thickness, which has an annual or even longer time scale. We see no other mechanism that could be responsible for the re-occurrence. Accordingly, we suggest that the fall T2M signal reemerges because of the still anomalous ice thickness.

Strongest anomalies are found in the winter before the event, especially for SLP and T2M, This is the only season that on average suggests a connection between anomalous atmospheric flow and T2M warming. In the forthcoming sections, we show that individual events or groups of events show stronger coherence.

\subsection{The role of the Arctic dipole anomaly (DA)}

To find dominant modes of sea level pressure (SLP) variability over the Arctic, we calculate Empirical Orthogonal Functions (EOFs) based on our simulated winter (JFM) means north of $70^{\circ} \mathrm{N}$ for the complete analysis period 1980-2079. A typical result is shown for scenario E1 (Fig. 5). The first EOF with a center over the Arctic Ocean is dominating the variability with an explained variance of $59 \%$ and represents the Arctic oscillation (AO). The second EOF mode with an explained variance of $15 \%$ shows an almost straight neutral (zero) line over the pole, and represents the Arctic dipole anomaly (DA) similar to Wu et al. (2006). Centers of oscillation are located over North America and Siberia. The third mode with a smaller explained variability of $9 \%$ is rotated by about $90^{\circ}$ compared to the DA. (As an alternative definition based on larger SLP fields between $10^{\circ} \mathrm{N}$ and $90^{\circ} \mathrm{N}$, the DA would result as the third principal component after AO/NAO (North Atlantic oscillation) and the Pacific-North America anomaly PNA; Overland and Wang, 2010). The associated principal component time series show no significant long-term trends, but annual-decadal variability. The distribution of the DA mode amplitudes for all 6 scenario experiments (Fig. 6, upper panel) shows a slightly skewed distribution with a maximum towards positive values. When selecting only the most extreme sea ice reduction events (Fig. 6, lower panel), we see exclusively positive amplitudes for the DA mode, while the leading AO mode and the nameless third EOF mode give both negative and positive amplitudes. The opposite selection of the remaining reduction events gives both negative and positive amplitudes for all three modes. Thus the most extreme rapid sea ice loss events are connected to positive DA anomalies during the winter before, which implies atmospheric warm inflow of Pacific origin into the Arctic. This finding is concordant with composite results for the $20 \%$ most extreme cases (composite \#4, Fig. 7a), also indicating increased atmospheric inflow from the Pacific sector. Wind anomalies can potentially change directions of ice movement and impact ice growth, thus affecting ice thickness. Sections 4.5 and 4.6 (e.g., case 16) show examples for such anomalies that persist until September.

It becomes clear that the most extreme cases of sea ice extent drop require a positive DA phase. Conversely, however, a positive DA phase does not guarantee a summer sea ice drop. Thus, a positive DA is a necessary, but not a sufficient condition for an extreme sea ice extent drop. This is again an expression of the role of meridionality for rapid change events.

Viewing the principal component time series in the example of Fig. 5, the DA amplitude is subject to interannual as well as to clearly visible interdecadal variability. High phases provide a precondition for a strong event. For low phases, the DA pattern is not decisive in providing conditions for a summer RILE.

\subsection{Composites}

To find out more about the major mechanisms connected to extreme sea ice events, we build composites based on selected members of the 30-member ensemble of rapid sea ice loss events. Selection criteria are chosen to cover the $20 \%$ (6 out of 30 events) most extreme events. We define composites based on either event summer or winter (before the summer event) conditions, and show resulting patterns for both winter and summer. Table 2 summarizes the different composites.

The composites \#1 and \#2 are defined by a warm respective cold winter (JFM) 2-m air temperatures (T2M) in comparison to the 10-yr reference period. Composite \#1 ("warm winter") covers winter air temperature anomalies greater than $3 \mathrm{~K}$, corresponding to the six warmest cases. Figure 7a (upper segment) shows the warming pattern together with other fields for that winter (before the event) and summer (of the event). This composite of warm winters results in the second largest summer event with an extent anomaly of $-274410^{3} \mathrm{~km}^{2}$ (see Table 2). The September ice concentration anomaly pattern is roughly coinciding with winter $\mathrm{T} 2 \mathrm{M}$ anomalies, indicating a distinct influence of the winter anomaly. Comparing patterns of winter T2M anomaly with winter SIT anomaly gives no agreement more than that generally thinner ice coincides with generally warmer air temperatures. There is no coinciding of the specific patterns.

Similar to the 30-case average in Sect. 4.3, we need to conclude that either the relationship between winter T2M and winter ice thickness anomaly is weak and other processes such as atmospheric transport of heat play a role, or the individual six events constituting this composite $\# 1$ are that much different that nonlinear effects are masking a relation between thickness and air temperature anomaly. Examination of specific events in Sect. 4.6 shows that thickness and air 
Table 2. Composites as explained in the text, with columns for anomalies of 2-m air temperature for September and winter (JFM), September sea ice concentration, and extent. Summer is defined by the three months JAS.

\begin{tabular}{lllrrrr}
\hline \# & Composite description & Figure & $\begin{array}{r}\text { Sept. } \\
\text { T2M } \\
\text { anomaly }\end{array}$ & $\begin{array}{r}\text { Winter } \\
\text { T2M } \\
\text { anomaly } \\
\text { K }\end{array}$ & $\begin{array}{r}\text { Sept. sea ice } \\
\text { concentration } \\
\text { anomaly } \\
(\text { SIC) }\end{array}$ & $\begin{array}{r}\text { Strength of } \\
\text { the extent } \\
\text { event } \\
10^{3} \mathrm{~km}^{2}\end{array}$ \\
\hline & & $7 \mathrm{a}$ & 1.3 & 3.0 & -0.33 & -2774 \\
1 & Winter T2M difference $>3 \mathrm{~K}$ & (no fig.) & 0.3 & -1.0 & -0.1 & -995 \\
2 & Winter T2M difference $<0 \mathrm{~K}$ & $7 \mathrm{a}$ & 1.2 & 2.9 & -0.27 & -2491 \\
3 & Summer SIC difference $<-0.134$ & $7 \mathrm{a}$ & 1.1 & 2.5 & -0.3 & -2937 \\
4 & Summer ice extent difference $<-241710^{3} \mathrm{~km}^{2}$ & $7 \mathrm{a}$ & 0.4 & 1.2 & -0.13 & -1333 \\
5 & Summer ice export velocity anomaly $>0.43 \mathrm{~cm} \mathrm{~s}^{-1}$ & 1.1 & 0.7 & -0.2 & -2008 \\
6 & Summer ice export velocity anomaly $<-1.99 \mathrm{~cm} \mathrm{~s}^{-1}$ & $7 \mathrm{~b}$ & 0.7 & 1.2 & -0.2 & -1818 \\
7 & Average summer (JAS) ice thickness $>70 \mathrm{~cm}$ & $7 \mathrm{~b}$ & 0.6 & 1.3 & -0.2 & -1489 \\
8 & Average summer (JAS) ice thickness $<70 \mathrm{~cm}$ & $7 \mathrm{~b}$ & 0.2 & \\
\hline
\end{tabular}

temperature anomalies widely agree, but atmospheric advection and ice movement play an important role as well.

The winter SLP anomaly shows a tripod-like pattern with three high pressure anomaly centers over Siberia, the northern North Atlantic Ocean and over North America. This winter SLP anomaly pattern seems to support anomalous air flow along the American and Russian coast. In terms of absolute SLP change, we see an intensified high pressure bridge between Siberia and Canada suggesting more meridional air flow. The core of the Iceland low is extended into the Nordic seas, suggesting increased atmospheric northward transports along the Norwegian coast and towards Spitsbergen, compatible with strongest warming north of Spitsbergen.

The September SIC anomaly shows strongest concentration reduction in the Spitsbergen sector and off the Alaska/Canada coastal area. An additional minimum is seen in the Laptev Sea.

Small negative concentration anomalies at the ice margins in Fig. 7a and b might be counter-intuitive but can be explained by small concentrations even during the reference period directly before the event (which might be anywhere on the scenario time axis), and by spatially different ice-free areas among the members of the composite.

Summer SIT shows strongest reduction along the transpolar drift path and is, as during winter, disparate from the SIC anomaly. SLP differences are small, weakening the central Arctic high and Siberian low. Such weaker meridional pressure gradients can potentially mean a more meridional flow on short weather time scales,

Composite \#3 ("low summer concentration") is defined by the lowest spatial average September sea ice concentrations compared to the reference period (" $\Delta \mathrm{SIC}<-0.134$ "). Those concentration anomalies (Fig. 7a, 2nd segment) are most negative on spatial average. Locally, other composites can show stronger reductions. This composite is also connected to a strong extent reduction (Table 2 ), slightly smaller $\left(\sim 400 \times 10^{3} \mathrm{~km}^{2}\right)$ than the most extreme composite (\#4). For this composite \#3 we find a winter T2M warming less in- tense than for composite \#1 ("warm winter"). The patterns of SLP anomalies and actual SLPs are very similar to composite \#1 ("warm winter") with less zonal flow, but winter SLP anomalies are less intense, as is the winter T2M anomaly. Summer SLP anomalies are similar to \#1 even in amplitude. Thus, we conclude that anomalous winter surface temperatures could be related to anomalous atmospheric circulation with reduced zonality.

Composite \#4 ("strongest drops") collects the most extreme losses of summer sea ice extent. Those drops ( $\Delta$ extent $<-2417 \times 10^{3} \mathrm{~km}^{2}$, Fig. 7a, 3rd segment) occur after a winter with warm surface temperatures over the sea ice except for the Greenlandic and Canadian coasts. In this case, thickness anomalies are roughly coinciding with the pattern of surface warming (unlike composites \#1 and \#2) in the Siberian sector and the central Arctic. The winter SLP anomaly shows a tripod pattern similar to \#1 and \#2, but with modified shape and amplitude. A high anomaly over North America is stronger and extended over Alaska and the Bering Sea. A high anomaly over the Nordic sea is intensified and extended towards Scandinavia. A high anomaly over Russia as visible in \#1 and \#2 has almost disappeared in \#4. Instead, a low anomaly covers much of the Arctic Ocean and Russia. The pattern consisting of the North American high and the central low anomaly bears some resemblance of the Arctic dipole anomaly (DA) pattern (Wu et al., 2006) in its positive phase. Both positive DA and the tripole seen here are suitable to foster atmospheric inflow from the Pacific area into the Arctic. EOF analysis in Sect. 4.4 confirms that indeed a strong positive state of DA oscillation is a necessary constituent for an extreme RILE. It is the tripod-like winter SLP anomaly pattern that dominates the all-event-winter average (Fig. 4a). As the pure DA pattern, SLP anomalies in the Pacific sector potentially bring warm air from the Pacific to the Arctic, helping to maintain a temperature anomaly.

The change of actual SLP patterns is less clear. Similar to previous composites, we see reduced zonality, which again potentially allows for meridional components on timescales 


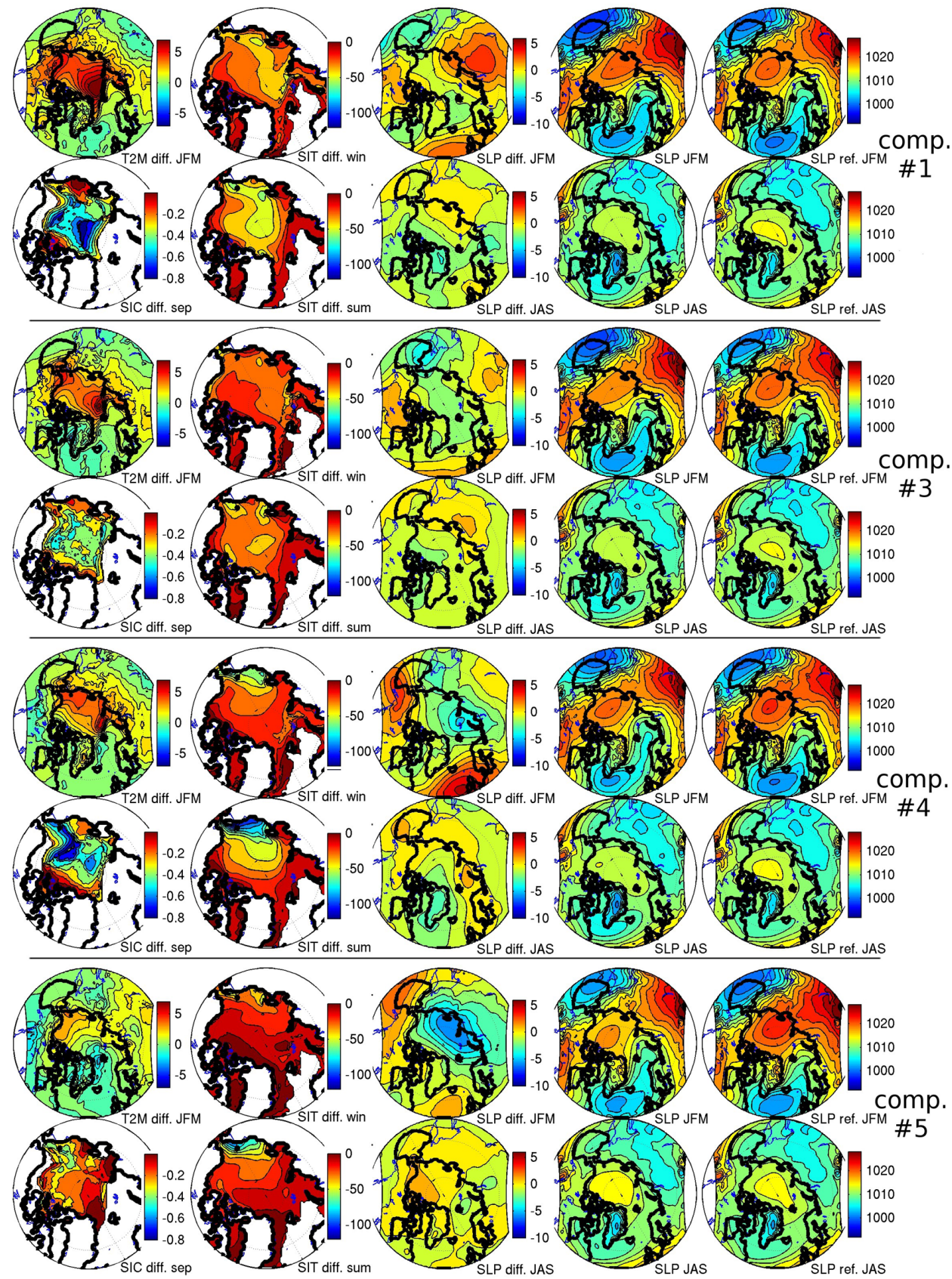

Fig. 7a. Composite fields in four segments for composites \#1, \#3, \#4 and \#5 as defined in Table 2: each segment contains an upper row (winter before the event) and a lower row (summer of the event). The upper rows show winter (JFM) T2M (2-m air temperature) difference in $\mathrm{K}$, winter SIT (sea ice thickness) difference in cm, winter SLP difference, SLP for the actual winter and reference period, and reference SLP in hPa. The lower rows show September SIC (sea ice concentration) difference, summer SIT difference in K, summer SLP difference, SLP and reference SLP in hPa. Differences refer to the difference between the actual season and the respective season of the 10-yr reference period.

shorter than a season. The actual winter SLP field shows a lengthened Iceland low extending far into the Barents Sea, which explains warmer temperatures over the nearby ice, i.e., that ice area where increased temperatures are not explained by a thickness or concentration anomaly.
During the summer of the event, we see centers of reduced ice concentration in the Atlantic sector and in the area between the pole, the Beaufort Sea and the Chukchi Sea in September. This is disparate from the summer thickness anomaly pattern, which gives strongest thinning in the East 


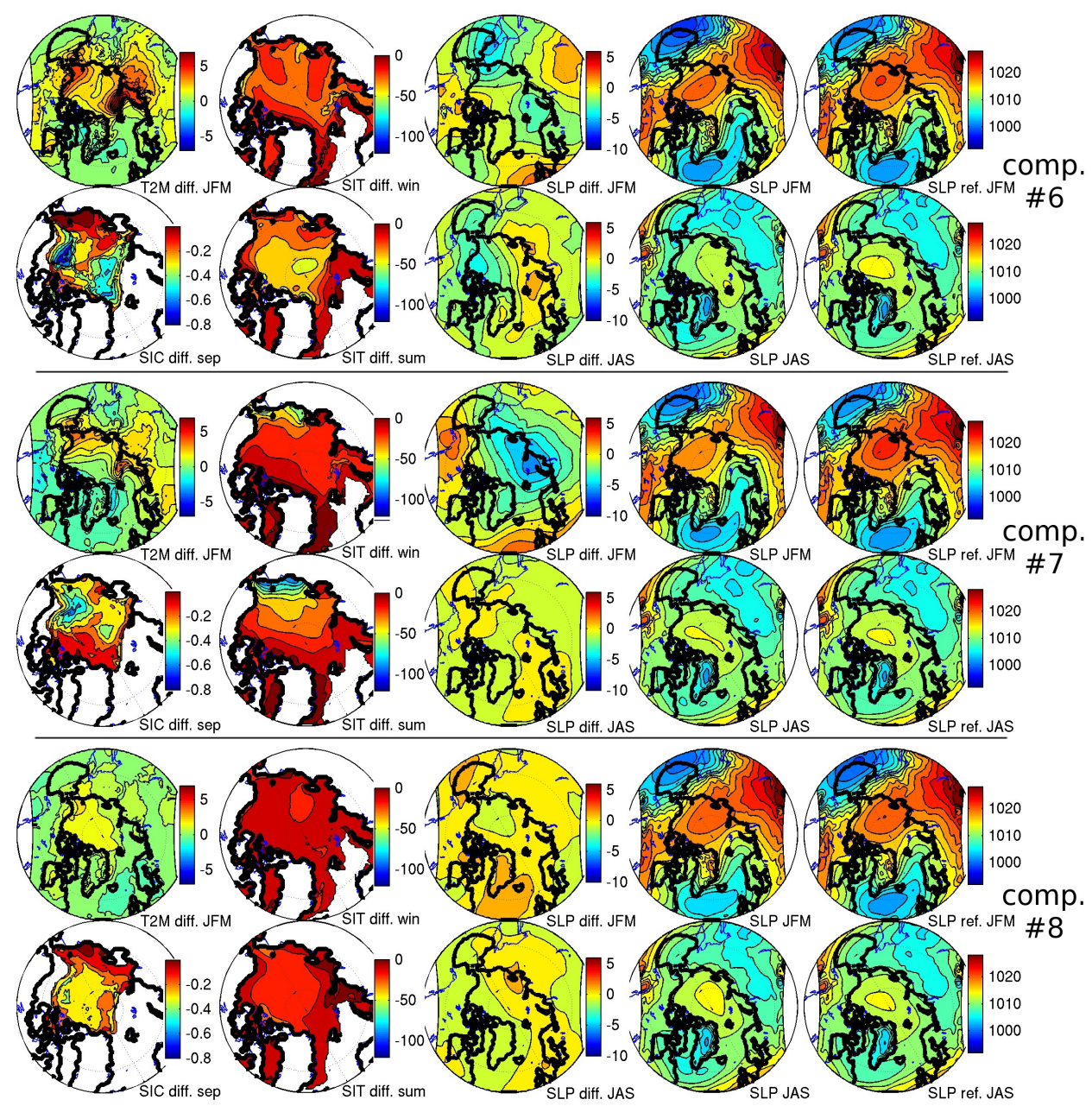

Fig. 7b. Composite fields in four segments for composites \#6, \#7 and \#8 as defined in Table 2: each segment contains an upper row (winter before the event) and a lower row (summer of the event). The upper rows show winter (JFM) T2M (2-m air temperature) difference in K, winter SIT (sea ice thickness) difference in $\mathrm{cm}$, winter SLP difference, SLP for the actual winter and reference period, and reference SLP in $\mathrm{hPa}$. The lower rows show September SIC (sea ice concentration) difference, summer SIT difference in K, summer SLP difference, SLP and reference SLP in hPa. Differences refer to the difference between the actual season and the respective season of the 10-yr reference period.

Siberian Sea and along the trans-polar drift. Instead, the centers of the summer concentration anomaly pattern resemble the winter T2M anomaly.

A summer atmospheric circulation anomaly is formed by a low pressure anomaly over Greenland and high anomalies over the Bering Sea and Kara Sea. It is the Kara Sea summer SLP anomaly pattern that dominates the all-event average during summer (Fig. 4a). Translated into change of actual SLP, this means again a reduced zonality compared to the 10 -yr reference period.

Thus, the strongest ice loss events are on average connected to distinct winter ice thickness anomalies. Together with enhanced atmospheric inflow into the region of Spitsbergen and the possibility of less zonal flow (i.e., stronger meridional flow components on shorter time scales), the winter warming anomaly can be explained. Starting from a win- ter with already thin ice in parts of the Arctic, summer SIC anomalies develop at locations close the places of strongest winter warming. Also during summer, we see reduced zonality in atmospheric flow.

Composite \#5 (Fig. 7a, segment 4) collects the most extreme cases in terms of summer sea ice export anomaly through Fram Strait. The strongest cases ("strong export") are connected to winter and summer SLP patterns with reduced anticyclonic atmospheric circulation in the Arctic, a reduced Beaufort Gyre and reduced ice transport into the Pacific sector. Instead, SLP is increased on the Greenland side of Fram Strait and reduced on the Barents Sea side, which indicates an atmospheric forcing of sea ice movement towards Fram Strait and must lead to enhanced sea ice transport through Fram Strait (Koenigk et al., 2006). 
In the opposite case ("weak export", \#6), events are connected to negative export anomaly, which is associated with a large-scale SLP pattern of opposite polarity suitable to hamper ice export.

Interestingly, the weak export composite \#6 gives a stronger summer ice loss event than the "strong export" composite. A SLP increase over the Barents Sea together with the SLP reduction over the Beaufort Sea leads to inflow from the Nordic seas. This is also visible in the summer absolute SLP pattern. Similar to several previous composites, we see a reduced central Arctic high, with a center moved towards Barents Sea, enabling inflow of warm air from the Nordic seas into the Fram Strait area. Accordingly, we see reduced September ice concentrations in that area. Another area of strongly reduced summer concentration is the Beaufort Sea, where a winter thickness anomaly was existing.

Both the "strong export" composite \#5 and the "weak export" composite \#6 show moderately strong amplitudes $\left(200810^{3} \mathrm{~km}^{2}\right.$ for the weak export and $133310^{3} \mathrm{~km}^{2}$ for the strong export). This indicates that the strength of sea ice export itself is not an important factor for generating rapid sea ice reductions in our model.

An additional composite pair (no figure) distinguishes onestep cases from two-step cases (see definition of events). Interestingly, the one-step composite gives figures very similar to the weak export case (composite \#6), confirming that strong single-step events require the summer inflow from the Atlantic sector. Two-step events are more dependent on the winter conditions with SLP anomalies very similar to the strongest events in composites \#1 and \#4.

An additional type of composite for rapid ice loss events with more than 6 members is calculated under conditions of thick ice and thin ice utilized here. As thickness is diminishing throughout the scenario simulations, we choose a rather low limit of $70 \mathrm{~cm}$ between the two composites. This gives us 12 thick events and 18 thin events. The "thick ice" composite \#7 shows anomaly fields similar to \#4 ("strongest drops"), but with reduced amplitudes in winter and summer. Thus, the interpretation of \#4 is applicable here as well to an extent. Regional winter warming is partly connected to preexisting thickness anomalies supported by changed advection patterns during winter. Rather small SLP changes during summer are connected to summer concentration anomalies at locations close to the winter surface temperature anomalies.

The composite \#8 for "thin ice" is characterized by rather small changes during winter (SLP and ice thickness). T2M over the ice is increased by the rather small amount of $1 \mathrm{~K}$ almost all over the Arctic sea ice. During summer, a homogeneous reduction of ice thickness except for the Russian coast is visible together with SLP anomalies similar to \#4 ("strongest drops"), indicating an influence of summer conditions rather than preconditioning during winter. This appears plausible in light of thin ice, which is more susceptible to short forcing events rather than seasonal memory.
Table 2 summarizes the composites. The relation between September SIC and strength of the event is quite linear. As to be expected, the event strength increases both with winter and summer T2M. Note that the combination of warmest T2M anomalies for winter and September (composite \#1) leads to a strong event, but is out-rivaled by a combination of more moderate (but still strong) T2M anomalies (composite \#4), pointing to influences of more flow pattern details and other effects.

\subsection{Individual cases}

To further assess mechanisms behind rapid reduction events, we also need to explore individual cases. With our definition of a rapid reduction event, we cover strong one-step events as well as events in several steps, i.e., involving a series of consecutive ice reductions from summer to summer. Most cases involve more than one step.

For further examination, here we choose case 1 (with reduced ice in the Pacific and Atlantic sectors), case 16 (with reduced sea ice off the Eurasian and Alaska coast), and case 26 (with reduced sea ice cover off northern Canada during summer). Anomalies in this section refer to the difference between a specific season and the corresponding 10-yr average season directly before the event. If the case is a multiple-step event, the $10-\mathrm{yr}$ reference period ends at the beginning of the first step.

Case 1 with a sea ice record minimum during summer (JAS) 1998 is a one-step event in the ice extent. Sequences with seasonal means starting two winters (JFM) before the summer event are shown in Fig. 8a-d.

The two preceding winters before the summer event both show anomalously warm atmospheric conditions over parts of the Arctic Ocean. In the winter 1997, strong warming of more than $5 \mathrm{~K}$ (Fig. 8c, d, 4th panel) between Spitsbergen, northern Greenland and the pole cannot be associated with SIC or SIT anomalies. Instead, it is compatible with inflow from the Fram Strait area and the Barents Sea, which both are warmer areas compared to the target area. During winter 1998, the pattern of T2M warming coincides with sea ice anomalies.

The sea ice thickness anomaly is largely negative already in winter and spring (AMJ) 1997 due to particularly strong thinning in the reference period, and shows first signatures of the 1998 event already during the summer 1997 as a response to anomalous winds from Alaska to the central Arctic. The typical central Arctic high is displaced towards Greenland, giving rise to broader atmospheric advection from North America to the central Arctic. The origin of the inflow is shifted from the North American continent (for the reference period) to the Pacific coastal area (spring 1997), which brings relatively warm winds to the Arctic. The effect of changed offshore winds is also seen in reduced SIC off Alaska.

During summer 1997, an elongated low pressure anomaly centered over the pole is connected to ice drift away from 

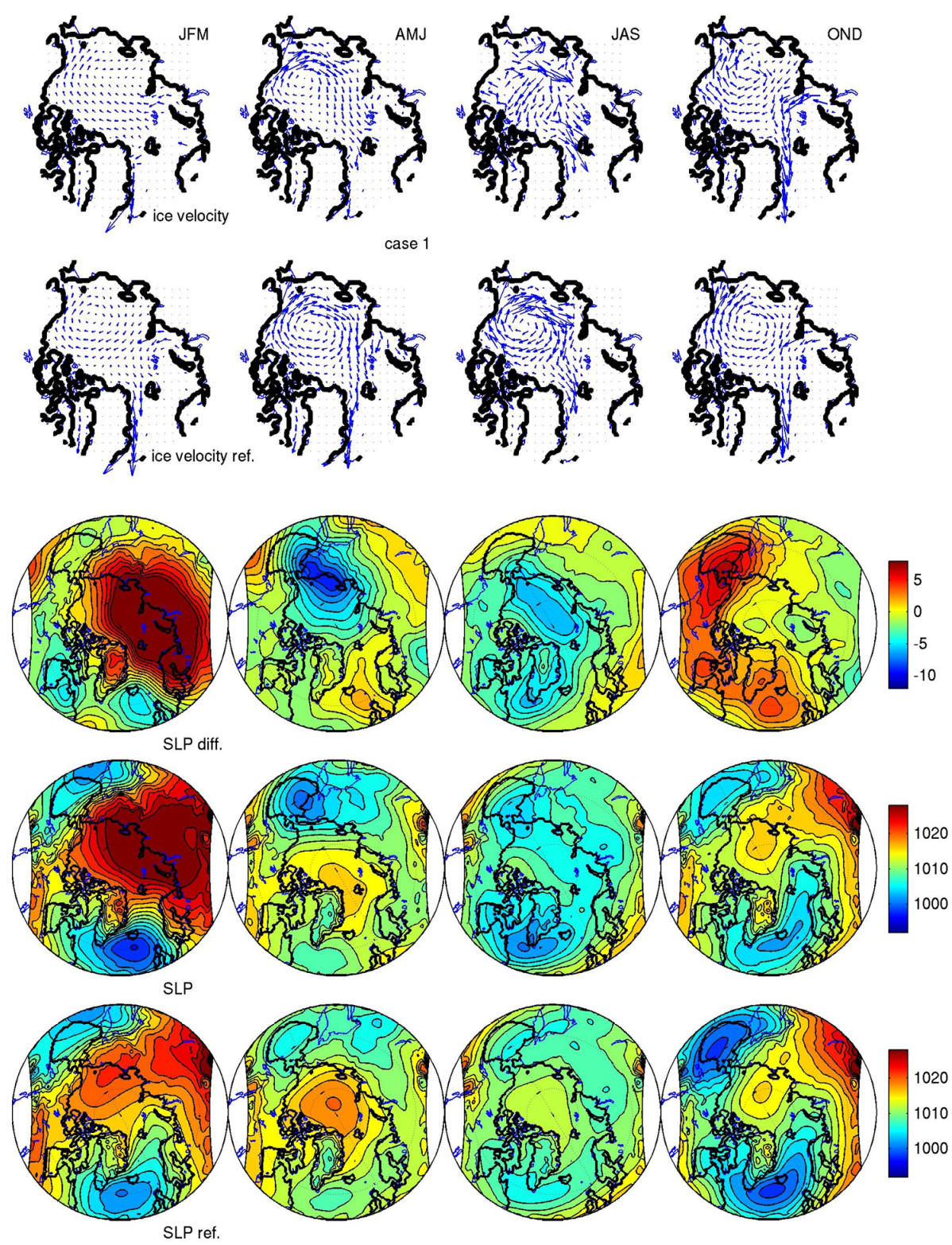

Fig. 8a. A sequence of seasonal means for case 1 during 1997, the year before the summer event. Sea ice velocity for 1997 (1st row) and for the reference period (2nd row), SLP difference between 1997 and the reference period (3rd row, in hPa), SLP of 1997 (4th row in hPa) and SLP of the reference period (5th row, in hPa). Rows represent seasonal means starting in winter (JFM) 1997.

Alaska towards Greenland. In terms of absolute SLP, this means a spatially less extended Arctic high with reduced SLP. The ice opening in spring off Alaska is also supported by increased longwave downward radiation (LWD, no figure). In most cases, the effect of increased LWD is compensated by increased upward longwave radiation. During this summer however, we see an increased net effect of longwave radiation $(\mathrm{LWN})$ between atmosphere and remaining sea ice over the Chukchi Sea. Although increased LWD might be in line with warm atmospheric advection, it also must be a result of the actual ice opening. The net effect described here is acting on the remaining ice, not on the leads, which suggests a possible positive feedback of open large leads on remaining ice in the vicinity.

Further analysis of a possible initiating role of LWD as a consequence of heat advection cannot be done in this study of seasonal mean, nor can it be ruled out as it fits with atmospheric advection pathways. Shortwave downward (SWD) anomalies (not shown) exist, but do not appear to be sufficient to make an imprint on ice thickness or concentration patterns.

The thickness anomaly pattern from summer 1997 with thinner ice in the Chukchi and Beaufort seas persists until the event summer 1998. T2M anomalies over the Chukchi Sea 

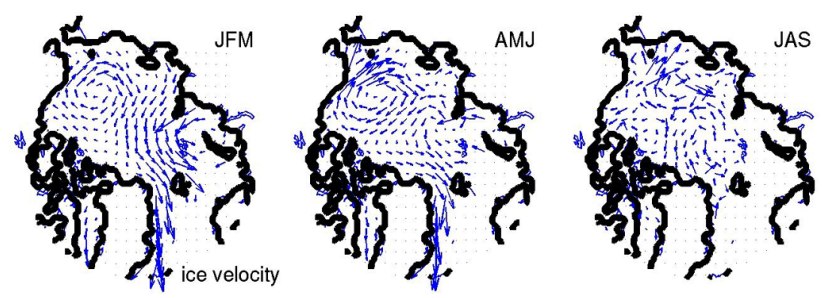

case 1
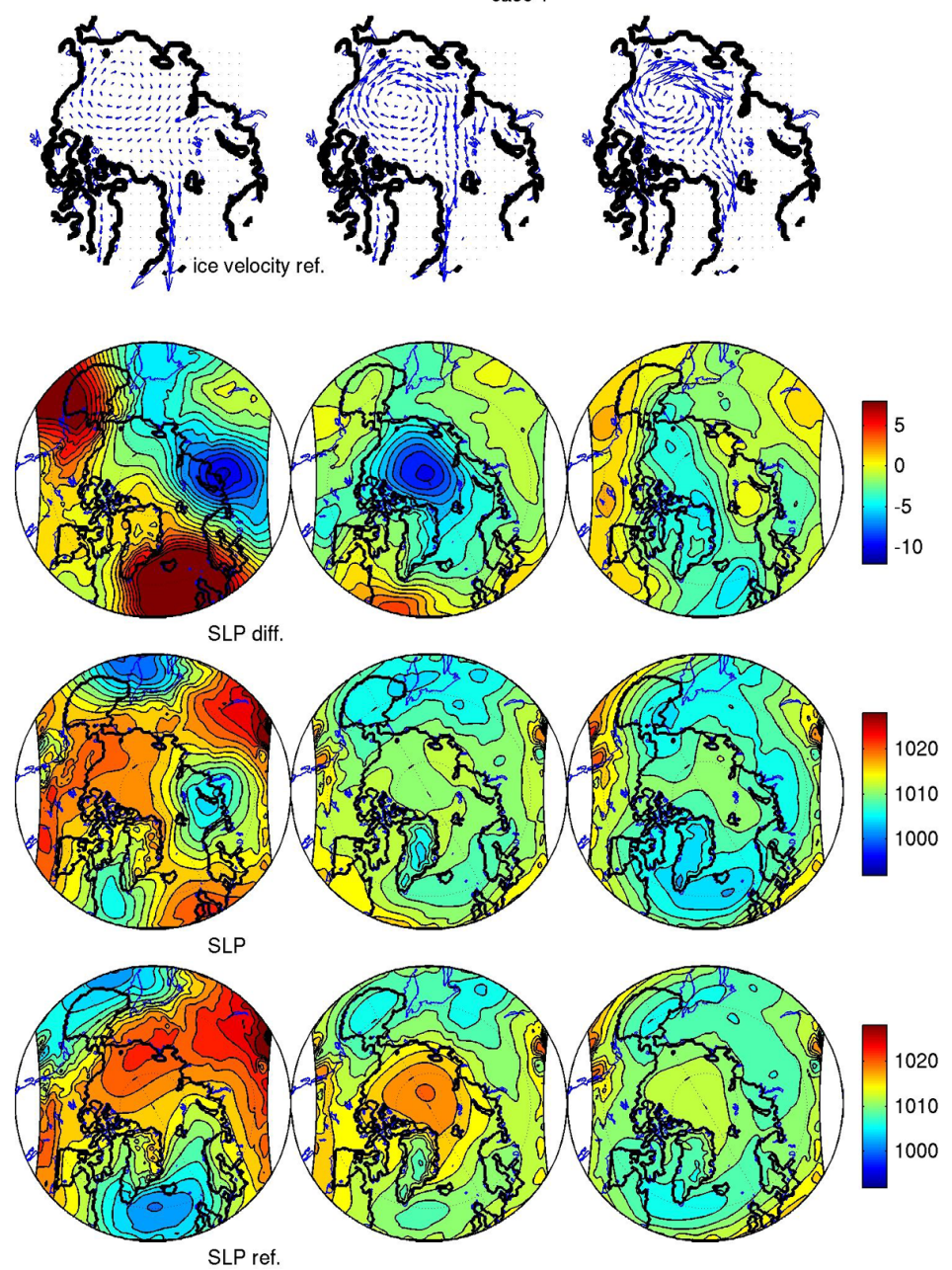

Fig. 8b. As for Fig. 8a, but for case 1 during 1998.

during fall (OND) 1997 and winter 1998 reflect the reduced ice thickness, but are even compatible with changed atmospheric flow. Fall atmospheric SLP patterns support an extension of the negative thickness anomaly towards the Laptev Sea (Fig. 8a, 3rd and 4th panel). The ice drift is reduced against the East Siberian coast and increased away from the Laptev coast in the winter (Fig. 8a, 1st panel). A slightly positive (into the ice) radiative LWN anomaly is seen over the Laptev Sea (Fig. 8c, 5th panel).

Eastern Siberian land areas are anomalously warm during that fall and winter, apparently due to relatively warm inflow from the Chukchi Sea, which shows strongest air temperature increase.

The winter SLP anomaly with high pressure over Alaska corresponds to a high amplitude of the winter DA anomaly pattern. Thus, an important precondition (according to Sect. 4.4) in the winter before the 1998 summer event is fulfilled. In the actual winter SLP pattern (Fig. 8b, 4th panel), a clear inflow from the warm Pacific Ocean is seen. Together with wind-driven ice drift away from the Laptev coast (Fig. 8b, 1st panel) and a stronger trans-polar drift, atmospheric circulation changes support survival of the negative thickness anomaly over the fall 1997 and winter 1998 LWD. 


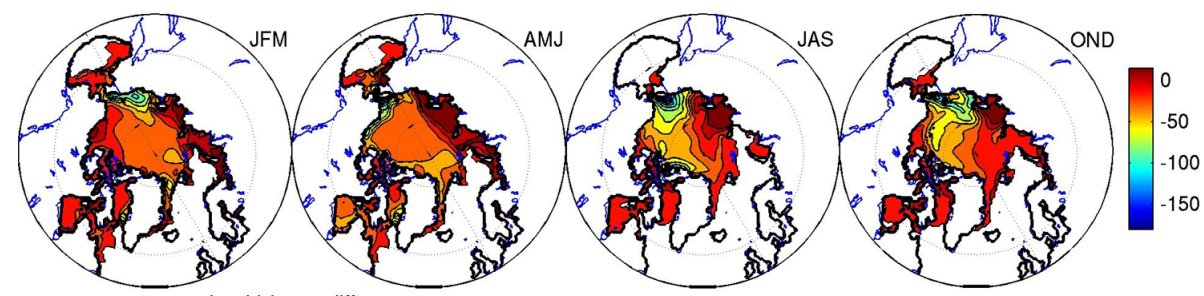

ice thickness diff. case 1

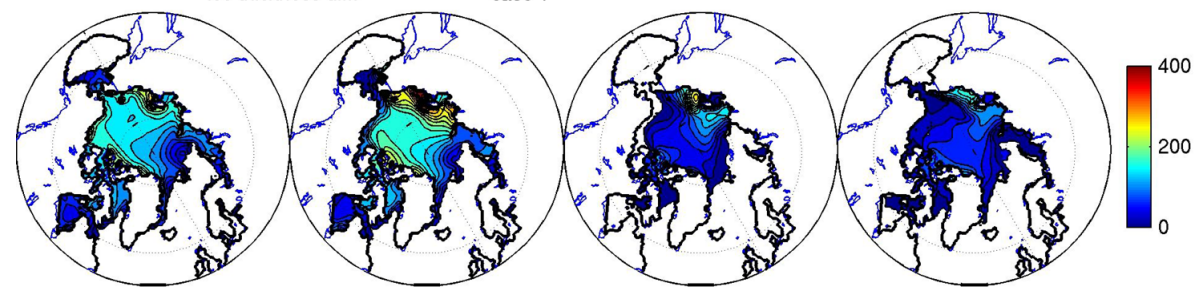

ice thickness
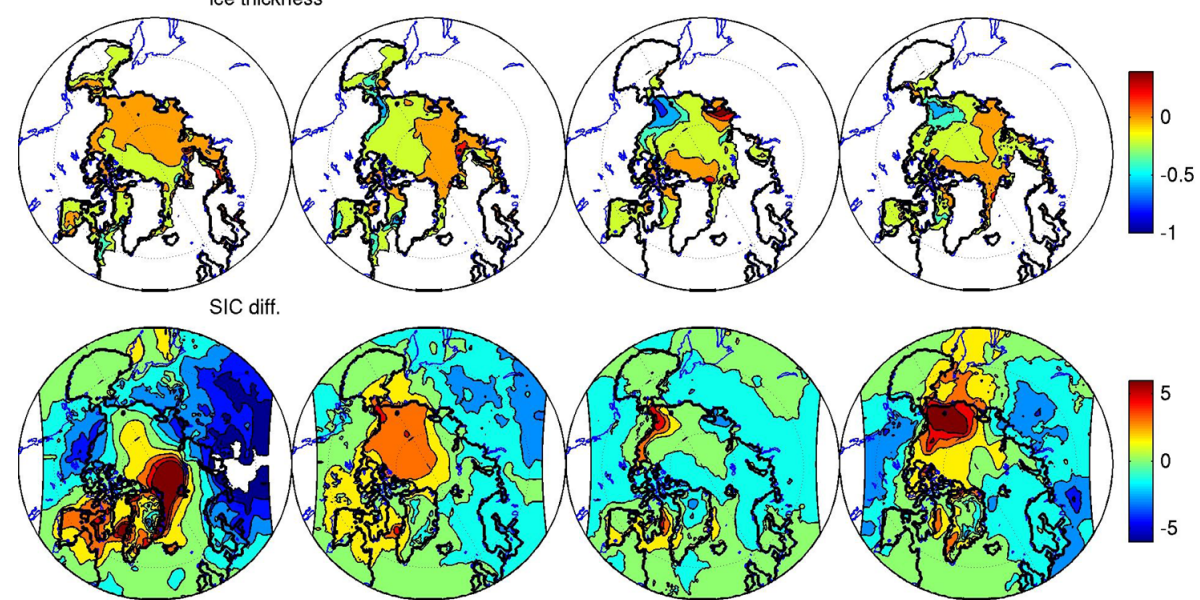

T2m diff.

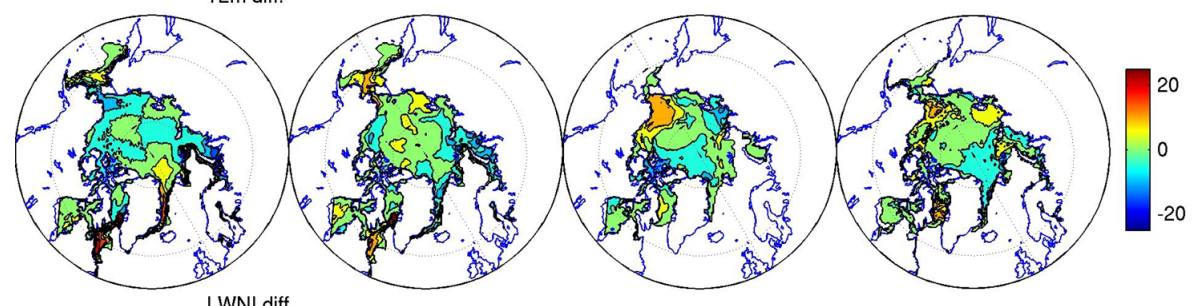

Fig. 8c. A sequence of seasonal means for case 1 during 1997, the year before the summer event. Sea ice thickness difference between 1997 and the reference period (1st row in $\mathrm{cm}$ ), for the reference period ( 2 nd row in $\mathrm{cm}$ ), SIC difference (3rd row), T2m difference (4th row in K) and LWNI (longwave net radiation over ice) difference (5th row, in $\mathrm{W} \mathrm{m}^{-2}$ ). Rows represent seasonal means starting in winter (JFM) 1997.

Again, increased LWD is widely compensated by increased upward longwave radiation leaving us with no net longwave contribution.

During spring 1998, the ice thickness anomaly is reflected by a generally warmer T2M over the Arctic Ocean, connected with a low pressure anomaly over the same area. The SLP anomaly means a reduction of the central Arctic high (Fig. 8b, 4th panel) with generally calmer and less zonal winds on seasonal average. This SLP effect during spring is consistent with observations, linear theory and and earlier model results. The geopotential height field should display a baroclinic response with a shallow low anomaly close to the warm anomaly (Walter et al., 2001). Alexander et al. (2004) find a local and direct baroclinic response to sea ice retraction connected to near-surface warming and below-normal sea level pressure. As for most parts of the year, increased levels of LWD are compensated during this spring.

During the event summer, a low pressure anomaly is concentrated in the Canada Basin and northern Greenland area (similar to the average event summer, Fig. 4a), connected with a reduced outflow from the eastern Arctic towards the Nordic seas and an enhanced inflow from the Nordic seas into the area north of Greenland. Again this implies a weakening of the central Arctic high with rather calm and more 

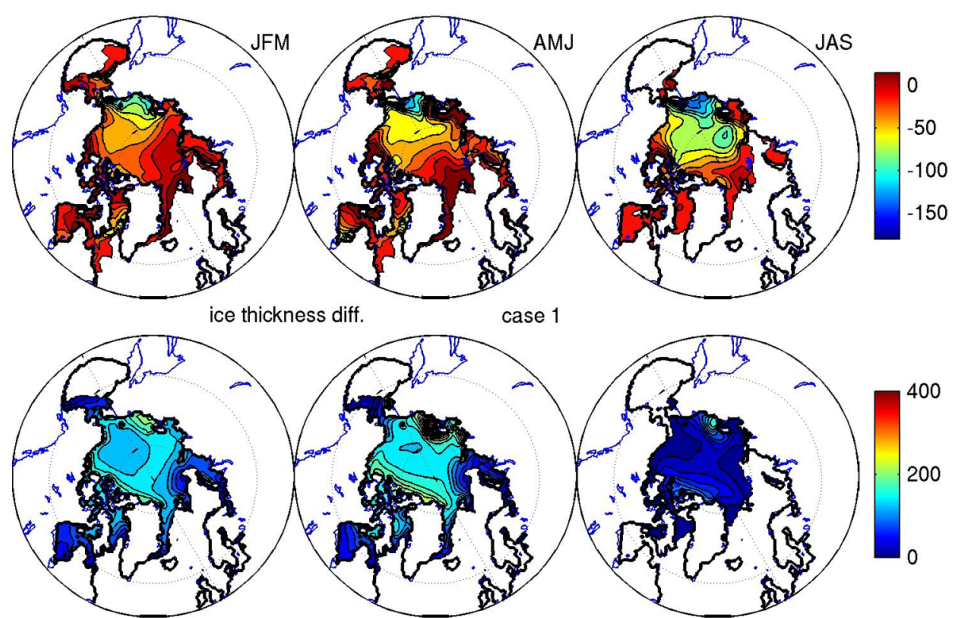

ice thickness

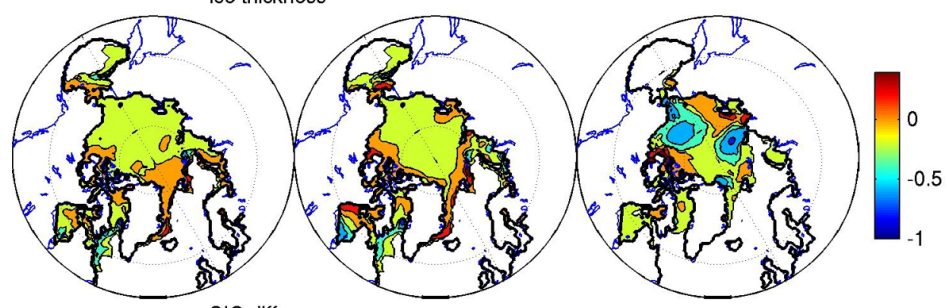

SIC diff.

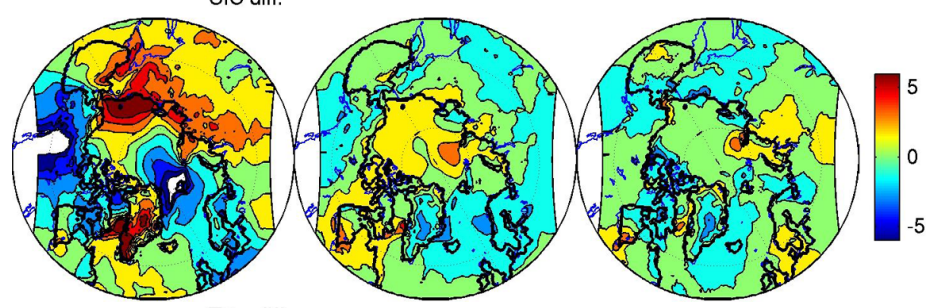

T2m diff.

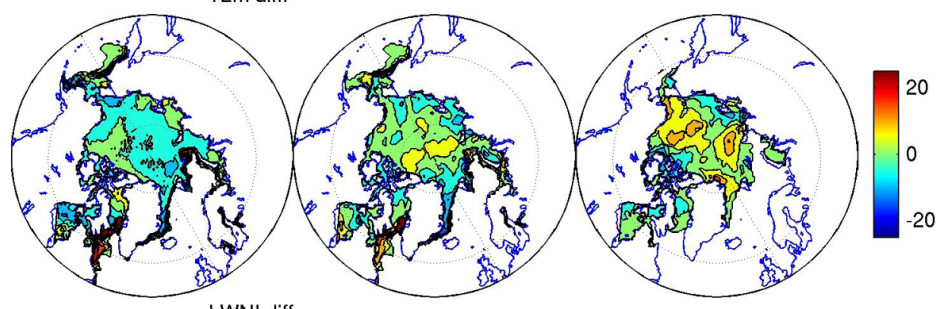

LWNI diff.

Fig. 8d. As Fig. 8c, but for case 1 during 1998.

meridional conditions and rather irregular ice movement (Fig. 8b, 1st panel), which allows the thickness anomaly to grow in about the shape that existed during spring and winter before. Sea ice export is weakened by the anomalous SLP as shown by the summer sea ice drift figures (Fig. 8b, 1st panel). This, however, does not prevent the summer loss. Similar to the previous summer, a net longwave radiative contribution is seen over the remaining ice on areas of reduced ice cover.

Both spring and summer 1998 show increased ice bottom melting (no figure). The fall and winter after the event show increased warming over large ocean and land areas. This warming reoccurs next fall (no figure) due to still reduced ice thickness.

Summarizing, a generally thin ice exists already during 1997, assisted by an additional circulation-driven thinning during spring/summer 1997 and winter 1997/1998, provided the preconditions for the 1998 event. The 1997 summer anomaly in the ice thickness survived the winter due to favorite meridional atmospheric circulation from a warm $\mathrm{Pa}-$ cific and due to anomalous ice drift away from the Laptev coast. After spring 1998 with very weak SLP gradients and calm conditions, the ice event culminated during summer, supported by atmospheric inflow over the Fram Strait area, 

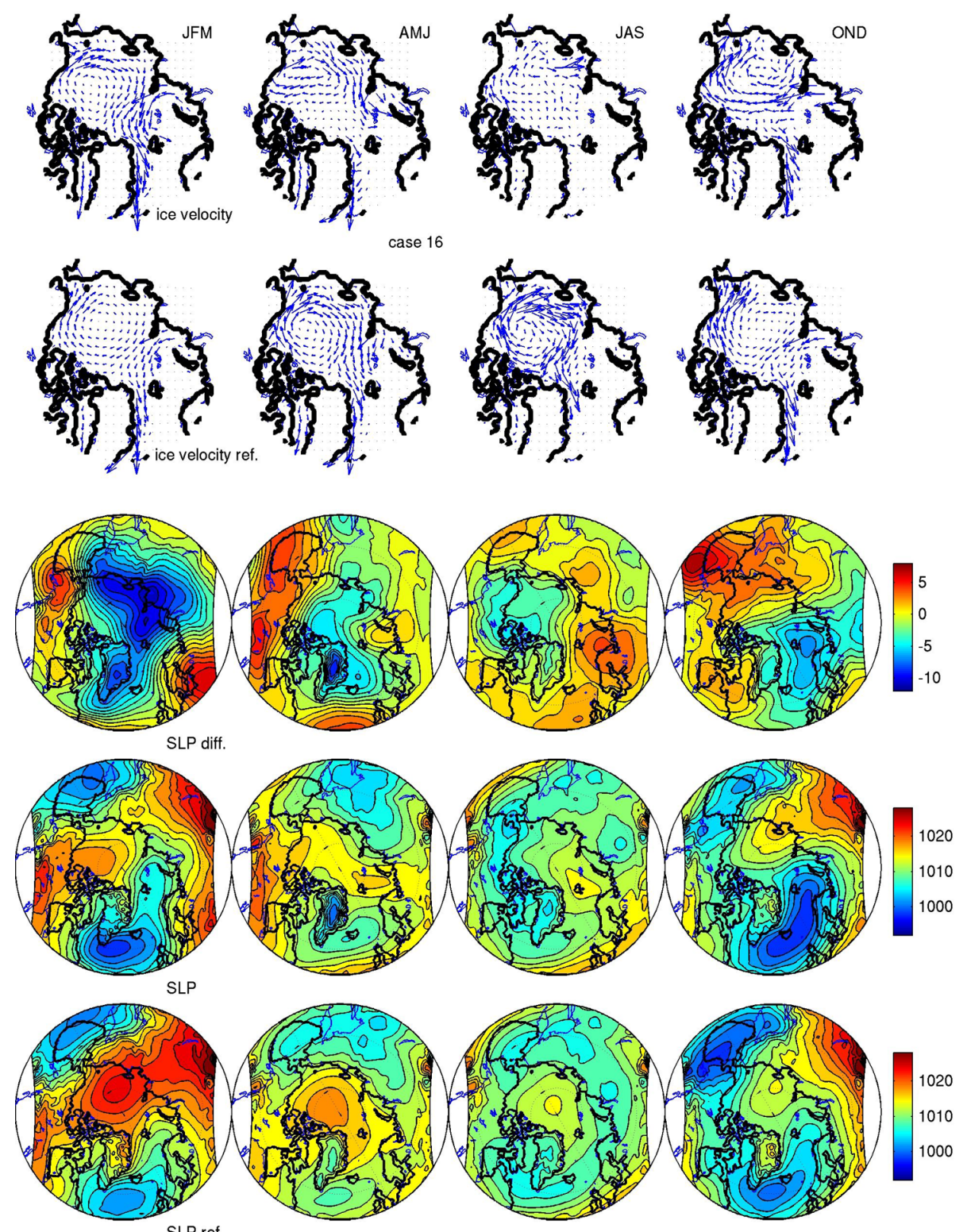

Fig. 9a. As Fig. 8a, but for case 16 during 2032.

carrying warm air. The net effect of upward and downward longwave radiation supports the ice anomaly during the actual event summer as well as during the previous summer.

Case 16 is a three-step event with a first drop of ice extent in summer 2031 following several decades of smaller variability. A large step in 2032 is followed by an additional smaller final drop in 2033. Figure 9a-d describe the case.

Similar to the winter of the event year in case 1, the falls and winters before the summer drop show positive T2M anomalies over the Chukchi and Siberian seas (Fig. 9c, d, 4th panel), reflecting areas with strongly reduced sea ice thickness. Other warm areas such as over Europe during winter $2031 / 32$ are connected to stronger inflow from southern lat- itudes. The initial negative ice thickness anomalies in the Chukchi and Siberian seas survive in about the same location and further develop all the way to the summer 2033. Two winters before the event show positive DA amplitudes, whereby the winter 2031/32 gives a stronger DA value. Positive DA values are illustrated by high pressure anomalies over the wider Alaska area and low pressure anomalies over the Eurasian Arctic Ocean and land (Fig. 9a and b, 3rd panel). Again and similar to case 1, the important precondition of strong meridionality (Sect. 4.4) during winters of the multistep event is given.

In both winters (JFM 2032 and JFM 2033), change of absolute SLP (Fig. 9a and b) shows increased inflow of air from 

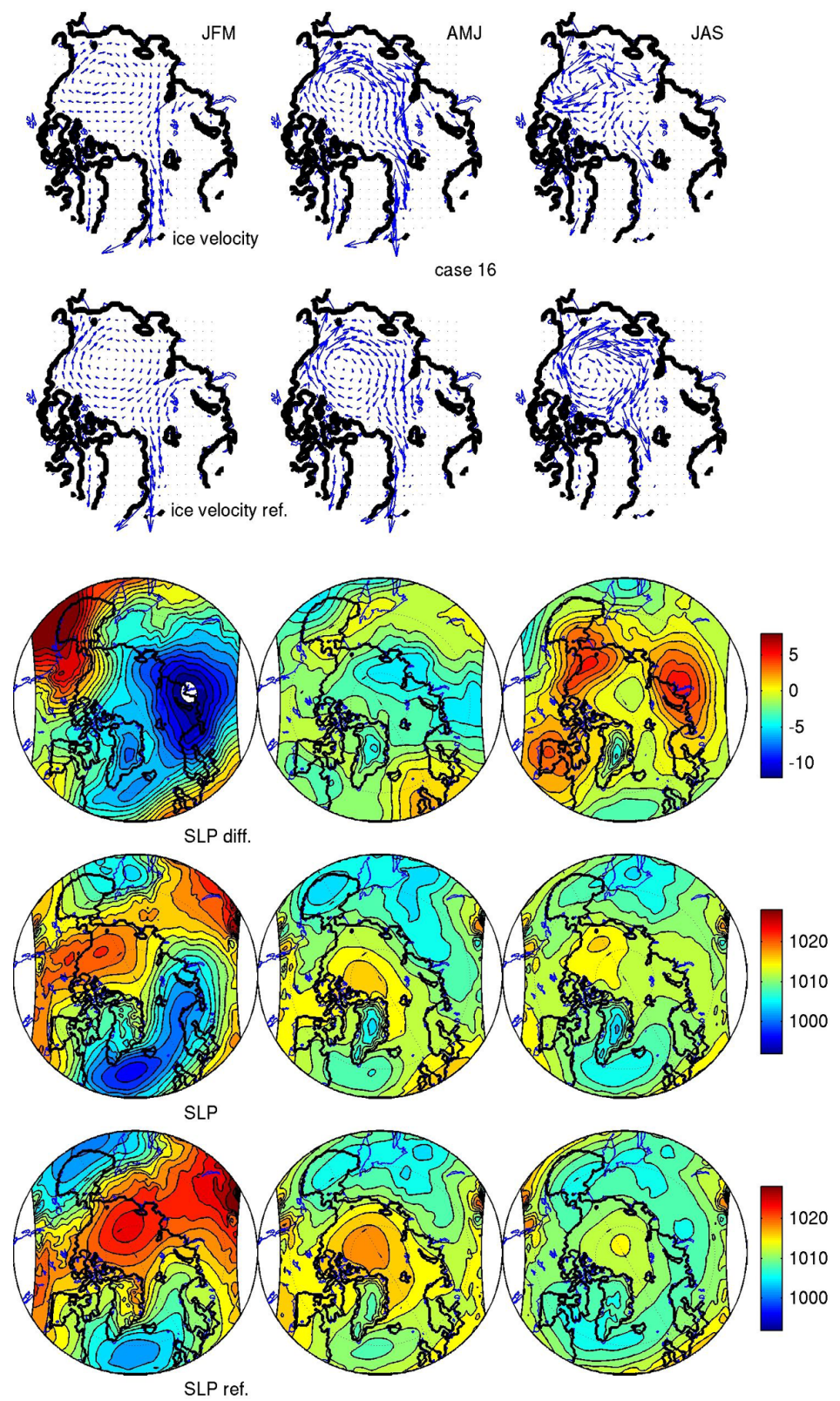

Fig. 9b. As Fig. 8a, but for case 16 during 2033.

the American west coast and Pacific area into the Chukchi Sea, and away from the West Siberian coast towards the central Arctic. Accordingly, sea ice drift along and away the Siberian coast is increased by wind forcing (Fig. 9a and b, upper panel compared to second panel). The anomalous ice movement is consistent with the reduced sea ice thickness in the Chukchi and East Siberian Sea extending towards the central Arctic and Fram Strait. The anomalous air flow driving the ice drift is originating in warmer areas, which also might contribute to the anomalously thin ice. This possibility is supported by anomalous positive longwave downward radiation (LWD, Fig. 9c, d) over the areas with thinner ice (the
Chukchi Sea is more strongly affected in JFM 2032 while the East Siberian Sea is more strongly affected in JFM 2033). However, as in the winters of case 1, increased LWD (no figure) is balanced by increased longwave upward radiation in a way that the net effect is close to zero (Fig. 9c, d, 5th panel).

Spring 2032 shows a broad inflow from the warm Pacific area, compatible with an extension of the sea ice thickness anomaly towards the Beaufort Sea. Consistent with the appearance of warm air, an increased LWD of up to $30 \mathrm{~W} \mathrm{~m}^{-2}$ occurs over the Beaufort Sea, which again is compensated for. At the same time, shortwave downward radiation is increased by about $30 \mathrm{~W} \mathrm{~m}^{-2}$ over the Chukchi Sea (no figure). 


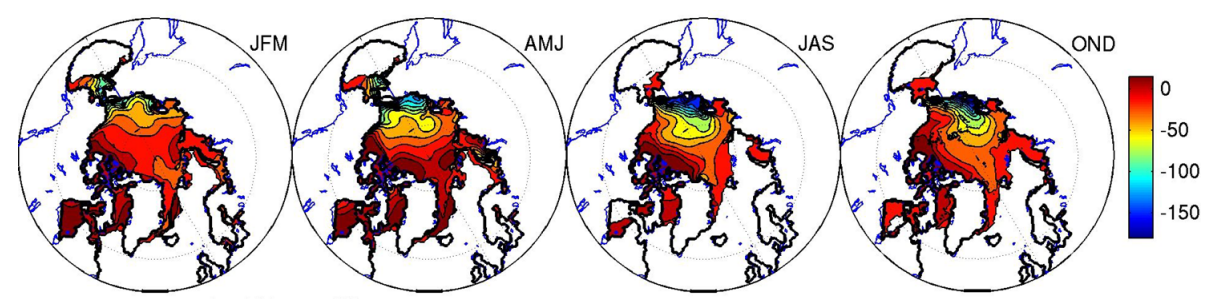

ice thickness diff case 16

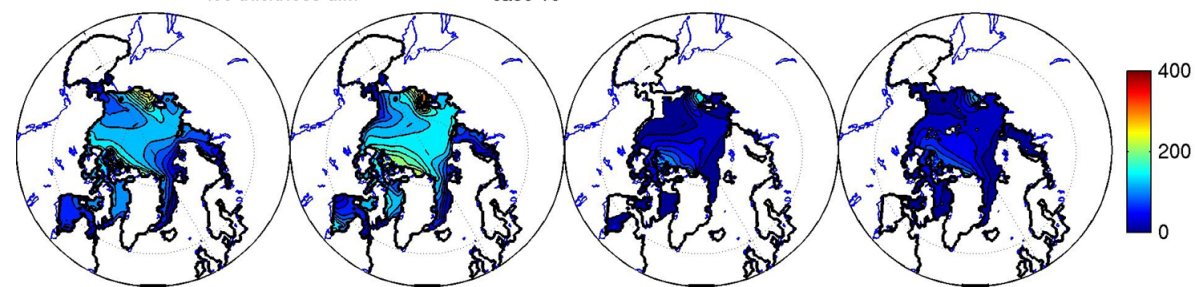

ice thickness
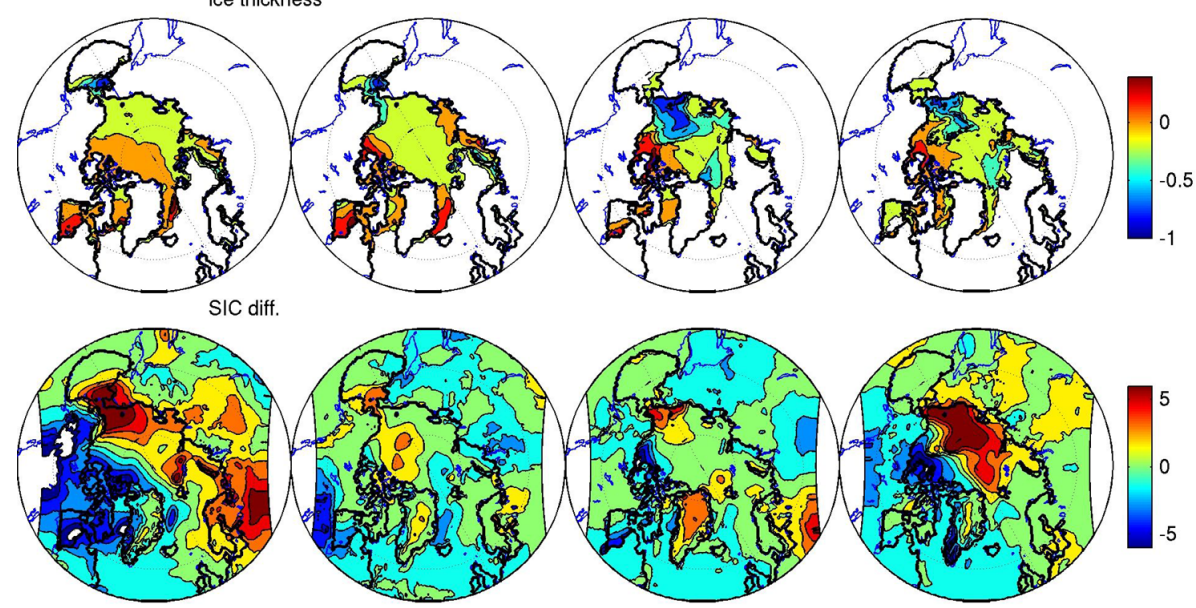

T2m diff.

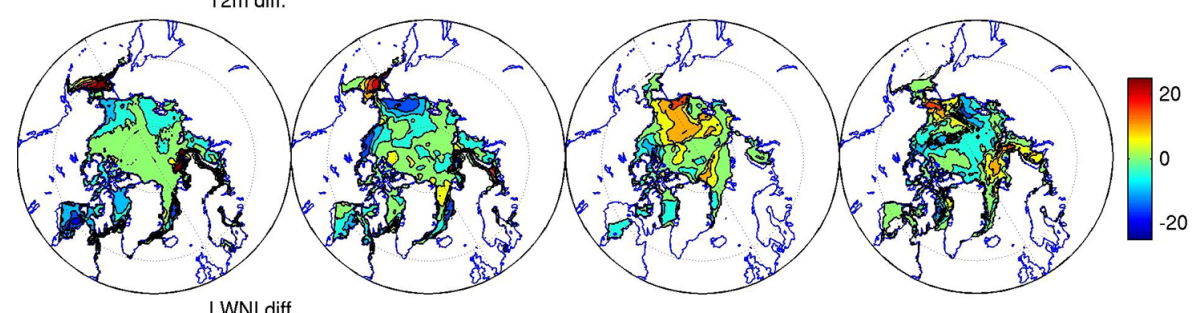

Fig. 9c. As Fig. 8c, but for case 16 during 2032.

Summer 2032 shows generally few anomalies. The SLP pattern (Fig. 9a, 3rd and 4th panel) implies inflow from the Nordic seas into the central Arctic. Consistently, there are also positive LWD anomalies over that region, which at this time even gives a net effect of up to $20 \mathrm{~W} \mathrm{~m}^{-2}$ contributing to ice melting. The ice thickness anomalies from the spring are intensified.

Fall 2032 shows an extended ice thickness anomaly in the Laptev Sea and the central Arctic, consistent with strengthened offshore air flow and ice drift in that region.

The winter 2033, as discussed above, shows anomalous air inflow from the Pacific, connected with an ice anomaly extended in shape. Anomalously thin ice in the
East Siberian Sea and the central Arctic is accompanied by a warm T2M anomaly.

Spring 2033 gives a stagnation and gradual retraction of the thickness anomaly. SLP shows a reduced central Arctic anticyclone spatially concentrated in the area north of Canada, connected to a more meridional flow over the pole, instead of anticyclonic circulation around the pole during the reference period. Increased ice drift from the pole area towards Fram Strait helps maintaining the ice anomaly.

Finally, the summer (JAS) 2033 shows a reinforced thickness anomaly and a sea ice concentration anomaly of a similar shape. The summer is also characterized by a central Arctic high pressure area displaced into the Chukchi Sea and 


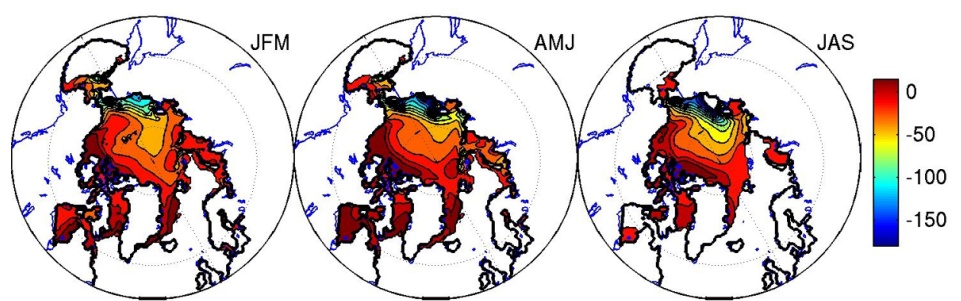

ice thickness diff. case 16

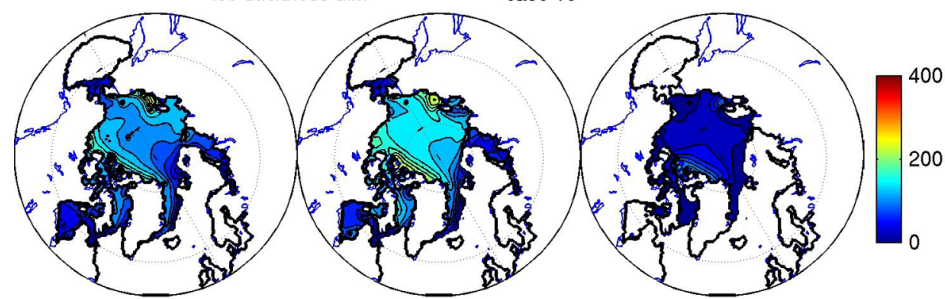

ice thickness

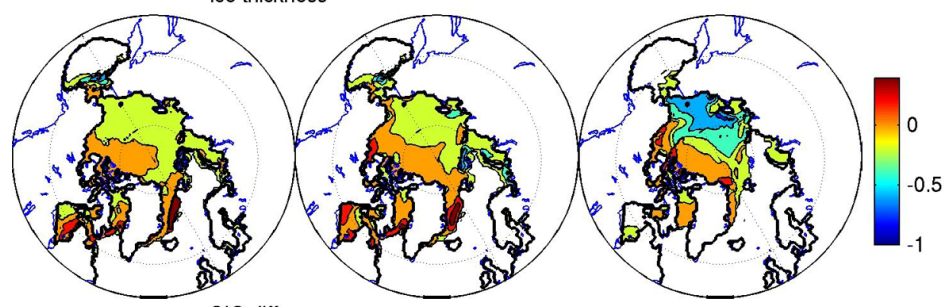

SIC diff.

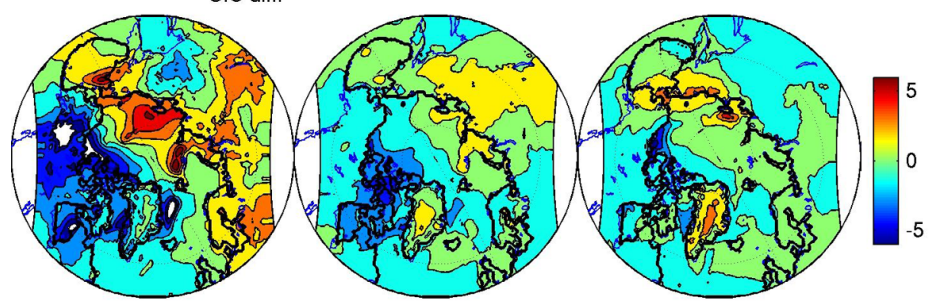

T2m diff.

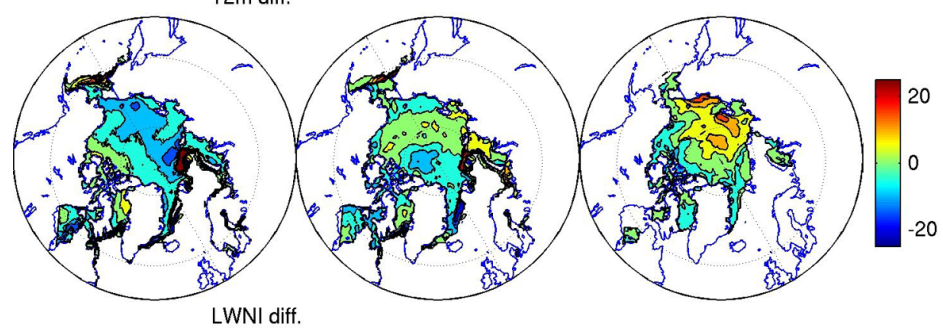

Fig. 9d. As Fig. 8c, but for case 16 during 2033.

strengthened. This is connected to ice drift from the Siberian and Laptev coast towards the central Arctic and towards the coasts of Canada and Greenland. The move of the central Arctic high is reflected in the SLP anomaly pattern by the tripod-like pattern already seen in the composite of the most extreme drops. Additional support for melting comes from a slightly positive longwave radiation anomaly over the remaining ice floes (LWNI).

During the summers (2032 and 2033), bottom melting is increased compared to the 10-yr average before the event. In principle this could be either due to reduced ice concentration and associated local water heating from the surface, or due to deeper ocean influences. To examine those possibilities, we explore the spring and summer 2032, which shows a distinctly positive SST (no figure) and negative ice concentration anomaly (Fig. 9b, 3rd panel) in the Chukchi and East Siberian seas. Winds drive away the ice from Chukchi Sea. Open waters occur, connected to immediate SST warming. A zone of increased bottom melting extends about 3 grid boxes (about $150 \mathrm{~km}$ ) under the ice and leads to additional ice concentration reduction until the wind driving stops. In that area of mixed ice and open water within individual grid boxes, the fraction of open water and bottom melting increases simultaneously. After an initial reduction 
of ice concentration, heat is absorbed by the upper ocean layer and immediately used for bottom melting, such that SST is not increasing for some time. In the given example we see a time delay of about 10 days between ice fraction opening and SST response. A mechanism similar in principle has been observed during the 2007 event by Perovich et al. (2008).

Summarizing case 16, initial thickness anomalies off the Siberian coast from the winter of the year before the summer minimum persist and strengthen in about unchanged center locations, supported by meridional winds, e.g., expressed by strong DA states in winters and warm winds from the Pacific area. Occasional offshore winds from western Siberia support ice movement away from the coast. Warm inflows are often confirmed by LWD anomalies. During the event summer, longwave radiation over remaining ice floats supports the final melt phase.

We also tested the idea of possible upward transport of original ocean heat by vertical mixing in response to reduced ice concentration. No sign of such a process was found in this model. We find locally increased vertical mixing at grid points with strongly reduced ice concentration, reaching down to several tens of meters, but the heat source is the surface, not the ocean.

Case 26 is a one-step event with a record sea ice extent minimum in 2025 after several decades of smaller variability on top of a downward trend (see Fig. 2, exp. E6). The actual event is largely driven during spring and summer 2025, as indicated by the horizontal pattern of the event summer's ice thinning, which becomes visible not before spring 2025 . However, the story of case 26 starts already two winters before the actual summer event (Fig. 10). During winter (JFM) 2024 a negative ice thickness anomaly of $30 \mathrm{~cm}$ and more is located in the Kara Sea, Laptev Sea and north of those areas. Even sea ice concentration is reduced in parts of the same area. The area is also target of atmospheric inflow originating from northern and western Europe during that winter, rather than from eastern Europe during the reference period's winter. Consistently, northern Russia is anomalously warm. This ice anomaly can now potentially survive the coming seasons if the atmospheric and oceanic conditions allow. The initial sea ice thickness anomaly persists until the record ice extent event and is joining up (during fall and winter before the summer event) with an additional ice thickness anomaly off Canada, compatible with anomalous meridional winds from the south from an anomalously warm northern Canada and coastal Pacific region. The winter before the summer event gives a moderately positive DA amplitude number, although the DA pattern is only slightly visible in Fig. 10b (4th panel). This potentially helps keeping the initial anomaly with winds from Alaska to the Fram Strait area. A few months later, during spring before the event summer, both initial sea ice thickness anomalies grow spatially and in amplitude with about unchanged center location. During summer, this leads to large areas of open water and low ice concentrations off the Canadian and northern Greenland coast reaching all the way to the Laptev sea, with ice remaining between the East Siberian coast and the pole. In the beginning of the melt season, the ice is too thin and depleted to survive the summer.

Thus, an important period for this event is the spring 2025, just a few months before the record summer. Increased spring thinning off Canada is related to an atmospheric low pressure anomaly covering the Beaufort Sea, the Bering Sea and larger coastal parts of Alaska and Canada. That anomalous atmospheric circulation allows for stronger winds from the Pacific coastal area and is compatible with the notion that off-shore winds press the ice away from the coast towards Chukchi Sea, without suppressing the initial Laptev ice anomaly. The anomalous winds can be seen both in the SLP anomaly as well as in the absolute SLP, which shows a central Arctic highly concentrated towards the Russian coast, opening up for winds away from Greenland/North America. At the same time, a slight SWD anomaly (of about $10 \mathrm{~W} \mathrm{~m}^{-2}$, no figure) is found off Canada to further support the local melting. A LWD anomaly of up to $20 \mathrm{~W} \mathrm{~m}^{-2}$ in the larger area north of Canada and Greenland indicates warm air. This must be partly due to the locally reducing ice and might be partly due to southerly advection from the Nordic seas. As described in several cases above, no net effect of longwave radiation on the ice can be seen in this spring, except in the coastal Beaufort Sea, which shows an ice opening at the same time (Fig. 10d, 2nd column). The seasonal means we are considering here do not allow for a more detailed analysis of the time sequence of influences.

Additional surface warming during spring occurs as a consequence of ice retreat. This in turn supports the further existence of the atmospheric low pressure anomaly, thereby potentially constituting a positive feedback with offshore winds away from the Canadian coast. The event summer shows the typical positive SLP anomaly (as seen in the 30-case average in Fig. 4a) over the Eurasian coast in a strong realization. In terms of absolute SLP changes, this means a geographical shift of the high-pressure center to the Eurasian coast with associated offshore winds away from the Canadian coast. During the event summer, a positive LWNI (longwave radiation over anomaly over remaining ice floats) supports melting. Already during spring 2025, both bottom melting and surface melting increase compared to the $10-\mathrm{yr}$ reference period, whereby bottom melting is increasing more than surface melting. During the event summer, bottom melting is still increased due to heat entering the ocean leads.

We see an event with early local sea ice anomalies in the seasons before and later maintained by supportive wind patterns during specific periods. The start signal of the actual event in the shape of the event summer is given in spring with opening up coastal areas and continued by air inflow from the Fram Strait area. This event is mainly driven by spring and summer atmospheric forcing. Also during spring we see a low pressure anomaly, which stabilizes ice melting. It also supports offshore ice transports in the Laptev Sea. Atmo- 

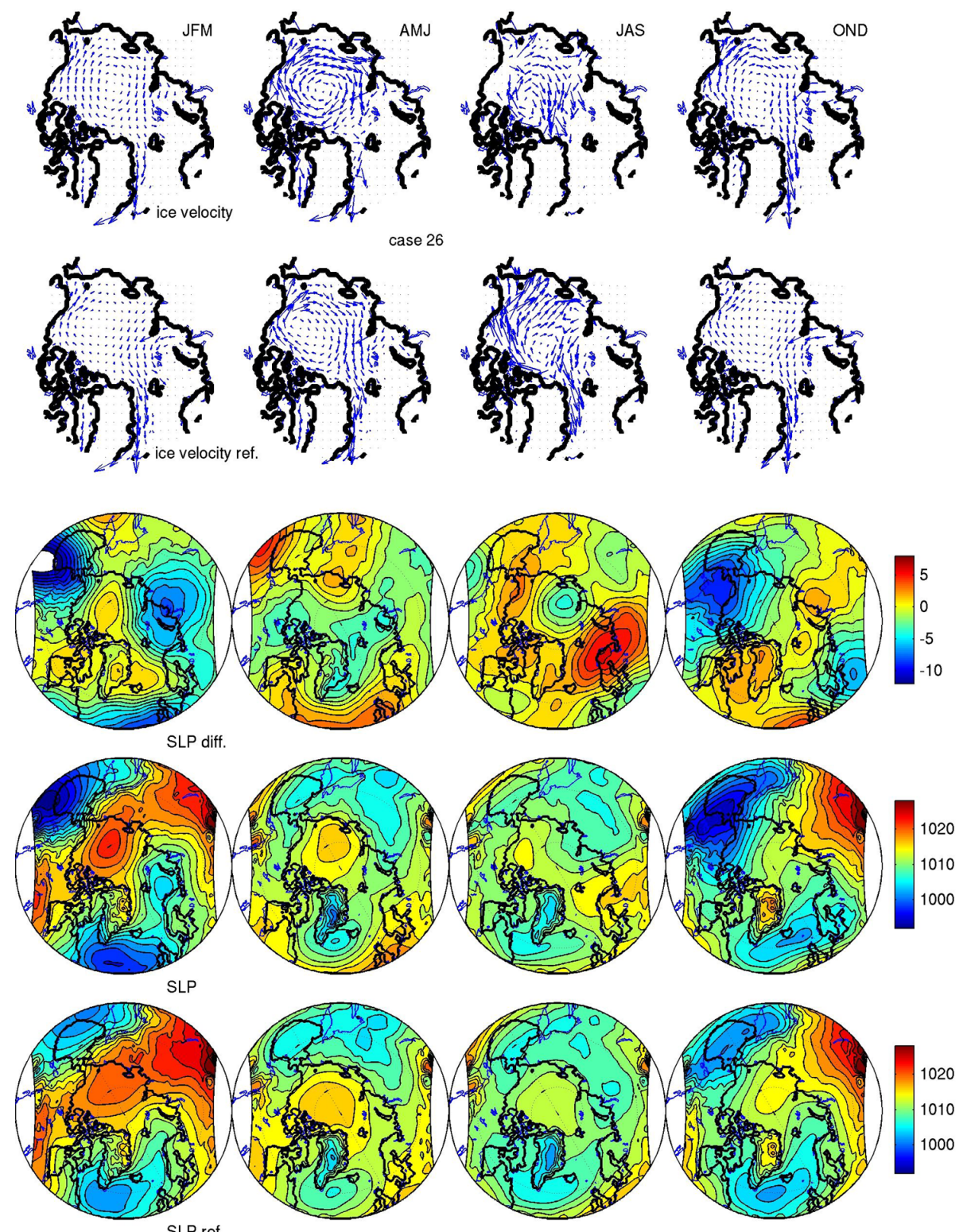

Fig. 10a. As Fig. 8a, but for case 26 during 2024.

spheric circulation sets the stage for shaping the conditions for a strong ice loss event. A potential positive feedback between warm surface and reduced SLP might be speculated.

Reviewing our three cases (cases 1, 16, 26), we find rapid ice change events with low ice concentrations in different parts of the Arctic Ocean. Each event is preconditioned by an initial sea ice thinning, which either was preexisting, or assisted by an atmospheric circulation anomaly, often connected to more meridional wind patterns that transport heat from warmer regions to the Arctic. Depending on the atmospheric conditions of the forthcoming seasons, the anomaly survives and grows during a period of $1-3 \mathrm{yr}$, modified by wind conditions, ice drift and partly regional dynamic feed- backs. Longwave net radiation anomalies contribute to melting during some springs or summers. Events can be dominated both from preconditioning or from summer atmospheric forcing conditions.

Each event is connected to increased bottom melting during the summer. The increased bottom melting is explained by large lead areas where atmospheric heat can be absorbed by the uppermost ocean layer and thereby contribute to bottom melting. We see no indication for a bottom melting initiated by large-scale heat fluxes in the ocean. Furthermore, we see no sign for decisive impact of radiative fluxes on triggering ice events. In some cases, radiative anomalies amplify melting. Longwave radiation anomalies are merely reflecting 

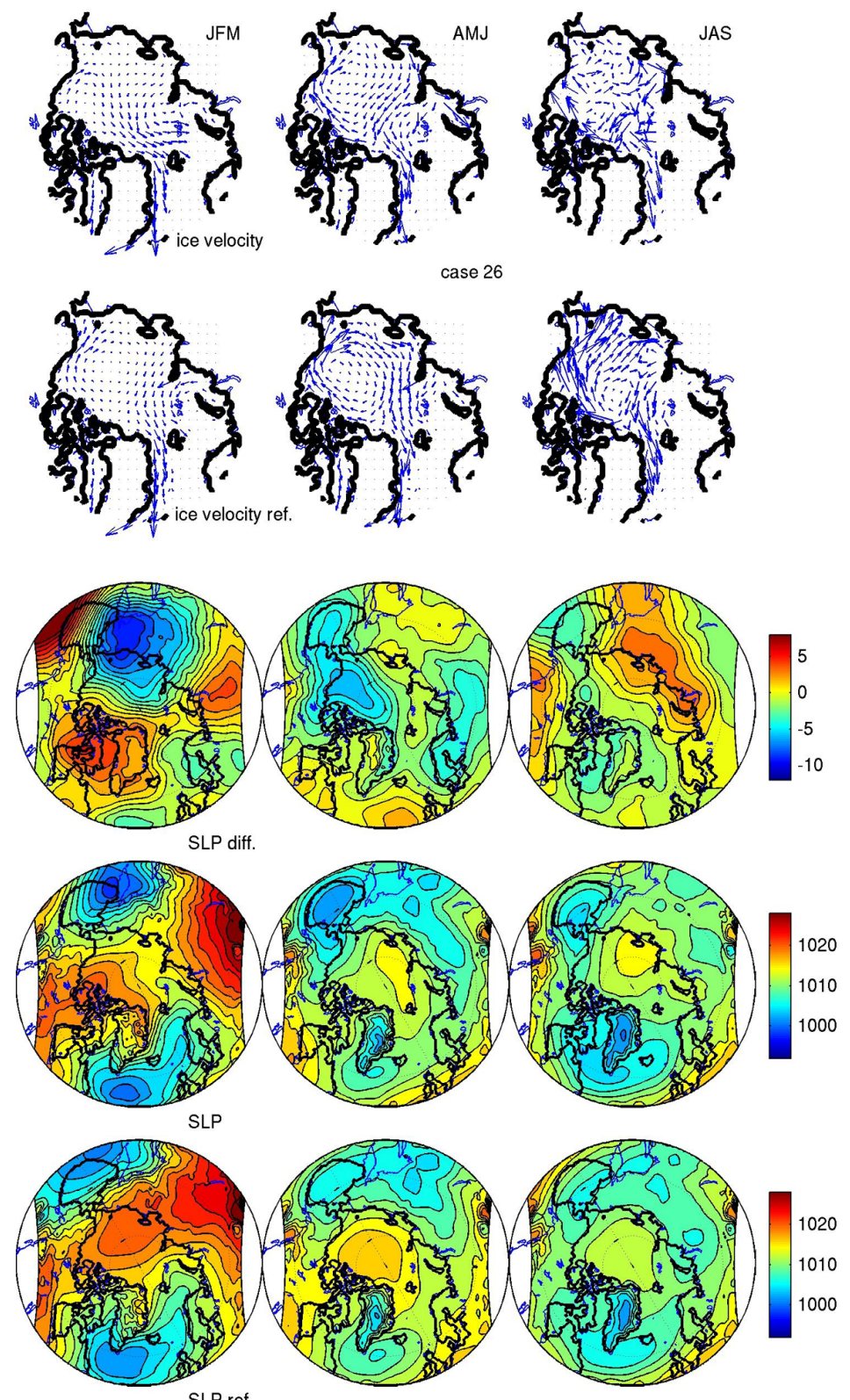

Fig. 10b. As Fig. 8a, but for case 26 during 2025.

surface air temperature changes, either due to ice opening or thinning, or due to advection of heat from warmer regions. For most seasons considered here, we find that longwave downward radiation is compensated by a corresponding upward radiation in response of a warmer surface. Only few cases are seen with a net effect of $20-30 \mathrm{~W} \mathrm{~m}^{-2}$, which supports the coming ice minimum. Occasionally we see summers with a supporting longwave radiation anomaly over small remaining ice floats. Shortwave solar radiation anomalies play a minor role only for generating the sea ice events in our model simulations. It appears hard to find examples of decisive influence of shortwave downward radiation. How- ever it should be noted that this finding is based on seasonal means. Consideration of shorter time periods could possibly give a more detailed picture.

In most cases (case 1 and 26), a warm air anomaly in spring is connected to a low pressure anomaly. In at least one case (case 26), we see indication for localized positive feedback between thin ice, connected to high surface air temperatures and a low pressure anomaly, which supports advection of new warm air into the area of thin ice. This is a selfsupporting mechanism that helps keeping or strengthening the initial thickness anomaly. Warm air anomalies during winter are generally not connected to low pressure anoma- 

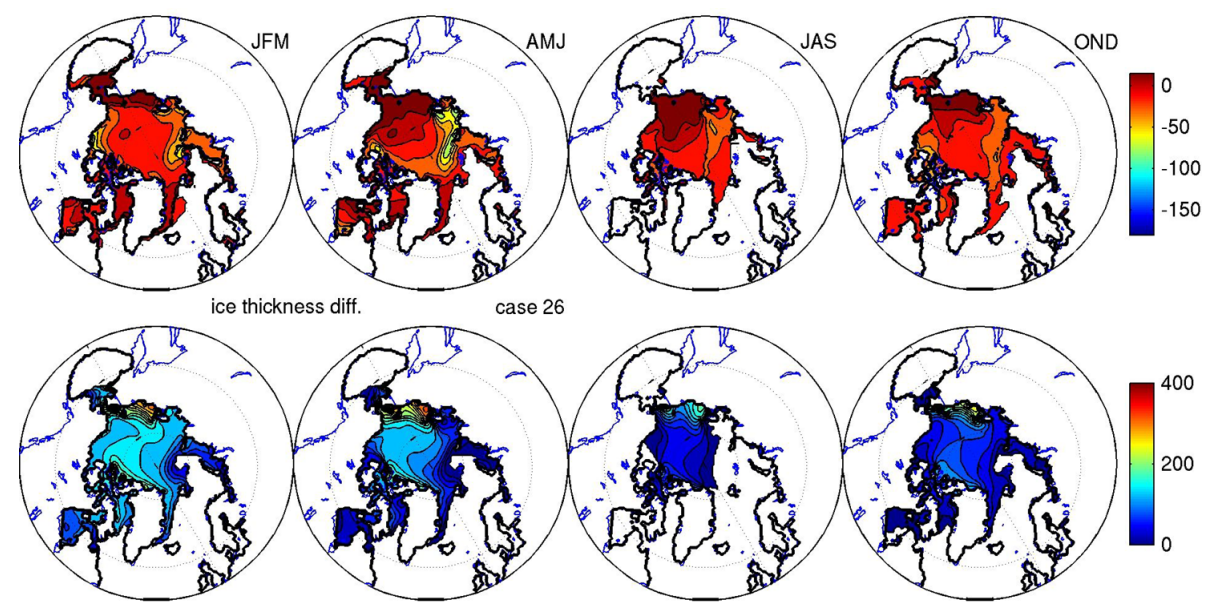

ice thickness
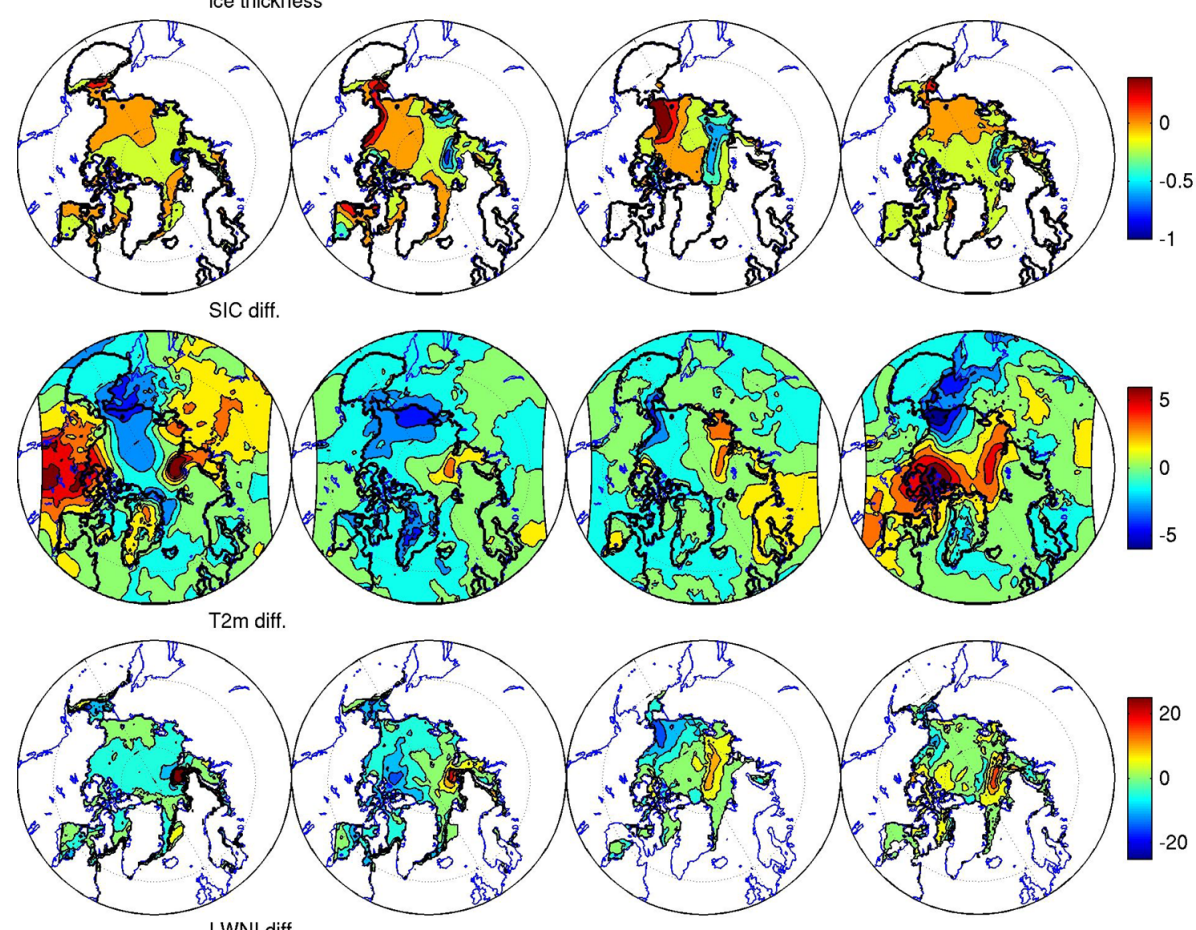

Fig. 10c. As Fig. 8c, but for case 26 during 2024.

lies at the surface. Fall and winter are more constrained by the large-scale circulation.

Atmospheric circulation patterns connected to positive DA anomalies, identified here as necessary but not sufficient winter preconditions for very strong events, clearly help in all three cases. All cases show positive DA anomalies, whereby two stronger ones are involved. Case 16 illustrates that a moderately positive DA supports the development towards the event, but the creation of the initial thickness signal is not necessarily connected to the DA.

\section{Summary and discussion}

We use a mini-ensemble of 6 different numerical Arctic climate scenario experiments each of 100 -yr length to investigate a total of 30 rapid sea ice loss events.

Summer sea ice extent decreases with time, and the likelihood of a rapid sea ice loss event increases with time and thus with thinning ice and reduced ice extent. In addition to the general trend of summer sea ice extent, we see decadal variability in all runs. Incoherent variability in time within the ensemble would point towards pure local Arctic selfcontained mechanisms (Döscher et al., 2010). However, we find similar interannual and interdecadal variability of summer sea ice among ensemble members. Thus, summer ice 


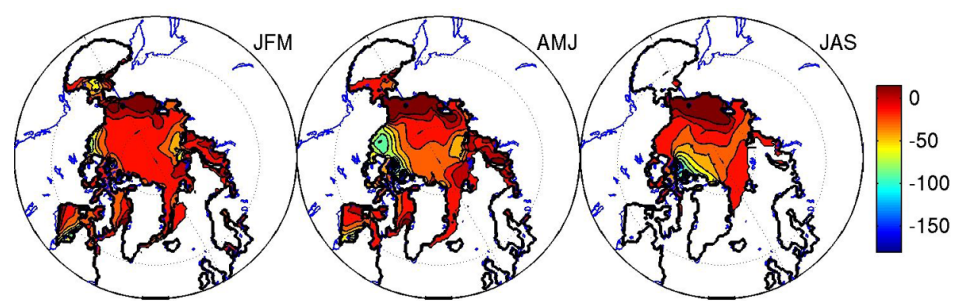

ice thickness diff. case 26

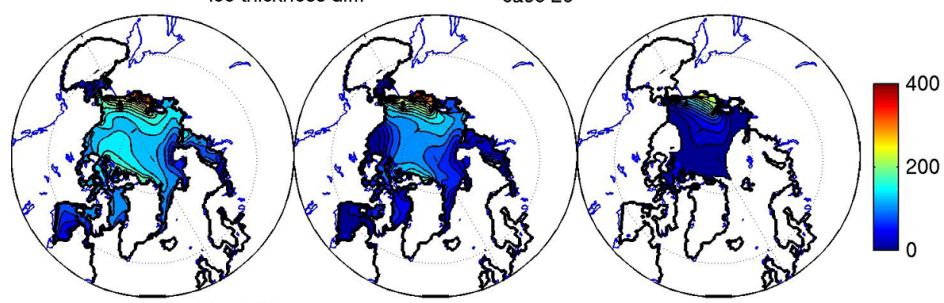

ice thickness

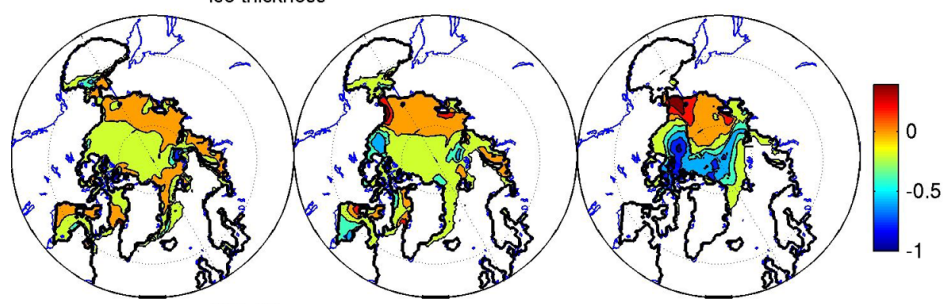

$\mathrm{SIC}$ diff.

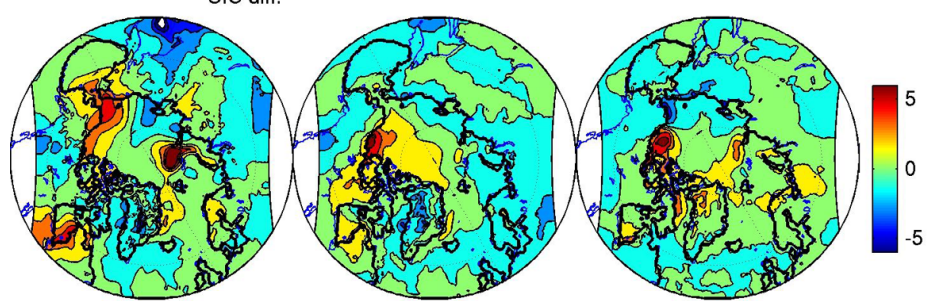

T2m diff.

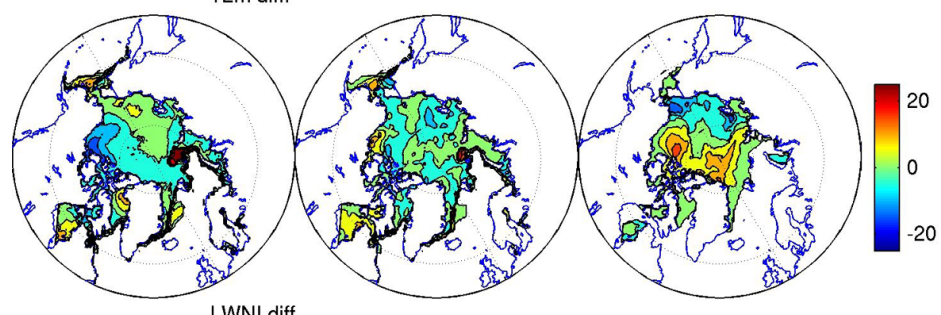

Fig. 10d. As Fig. 8c, but for case 26 during 2025.

extent is partly governed by global-scale atmospheric circulation, which in our regional model, at the outer boundaries, is enforced by lateral atmospheric boundary conditions identical to all regional runs.

In addition to common variability, we see clustering of RILEs during certain periods in the different scenario experiments. Large-scale atmospheric circulation, supportive in reducing thick ice off the Siberian coast, provides a strong potential for a RILE, so that many ensemble members actually generate events.

In our model, sea ice is generally too thin, as judged from the first decades of the scenario experiments. In addition, ice in the Siberian Sea tends to be artificially thick as a result of insufficient treatment of ice classes (Mårtensson et al., 2012) and likely due to a high pressure bias over the Eurasian part of the Arctic Ocean. This problem is shared with other regional climate models (RCMs) (e.g., Cassano et al., 2011) and GCMs (e.g., Vancoppenolle, 2008; Blanchard et al., 2011). Thus, results of this paper might help interpreting other models. Given that the artificially thick Siberian ice blocks rapid ice loss events under atmospheric circulation regimes (which do not oppose that exaggerated thickness), it might be speculated that a more realistic geographical ice thickness distribution could lead to even more frequent rapid 
ice loss events in our model. Our event case 26, timed during 2025, features a strong ice reduction off northern Greenland and northern Canada connected to ice drift away from those coasts. In such a situation, generally thinner ice off eastern Siberia can potentially lead to an even stronger event coming close to zero sea ice extent during summer. Thus, almost ice-free summers could be possible even before 2040. Conversely and generally spoken - specific geographical thickness distributions can block effects of atmospheric forcing, which potentially could generate a rapid loss event.

A RILE in the given climate change experiments can be evoked by specific forcing conditions applied on the sea ice affecting the winter before the summer event, or by spring and summer atmospheric forcing. Winter conditions are preconditioning the coming summer, but not necessarily leading to an ice reduction event.

On average, rapid reduction events are characterized by increased temperatures over the ice during the winter before a summer event (Fig. 4a). Warmer air temperatures mostly reflect sea ice thickness anomalies, but are in several individual cases also consistent with atmospheric circulation anomalies connecting warmer areas with the Arctic Ocean and impede sea ice growth, thus leading to reduced thickness already during that winter. Examples are the winter 1997/98 in case 1, the two winters before the summer event in case 16 , and the 2023/24 winter in case 26. Composite \#1 with strongest winter temperature anomalies is connected with anomalous inflow from a warmer north-west America and a warmer Europe while no coherence with sea ice thickness is seen (Sect. 4.5, Fig. 7a). In cases with increased winter surface temperature only over the ocean, anomalous meridional winds are often consistent with ice thinning in coastal areas were those winds are directed off-shore. This indicates ice drift. An example for the latter is the last winter before the summer event in case 26 .

Average summer conditions feature a high pressure anomaly along the Eurasian coast, and a slight negative anomaly over Greenland and the northern Canada coast, balancing an anomalous atmospheric inflow from the Nordic seas into the Arctic, or a reduced outflow from the Arctic. The average summer event shows even increased melting at the bottom of the ice.

Those average conditions give a very general picture, because individual cases vary in mechanism and geographical location. Inspection of specific cases (Sect. 4.6) helps interpreting the 30-case average results. Individual cases show, for example, that anomalous, increased atmospheric inflow from the Nordic seas during summer is realized by warm inflow from the Nordic seas to the Fram Strait area. Specific case studies (Sect. 4.6) show that a winter thickness anomaly can already be preexisting in the winter before the summer event. In those cases, the atmospheric conditions during the year before are responsible for the initial thinning.

Composites of specific atmosphere and sea ice conditions reveal that the most extreme drops in sea ice extent oc- cur in the combined case of a pre-existing winter thickness anomaly, atmospheric warming due to air advection and thin ice, and generally reduced zonality of atmospheric flow in winter and summer. Winter surface warming can often be explained by combinations of ice thinning and anomalous atmospheric flow. This is affirmed by an EOF analysis showing exclusively positive amplitudes for the DA anomaly (defined as the 2nd EOF of seasonal mean SLP north of $70^{\circ} \mathrm{N}$ ) for the most extreme drop cases, meaning increased pressure over North America and Greenland combined with reduced pressure over northern Eurasia. We conclude that the most extreme sea ice drops are not possible without a positive DA phase during winter. Analysis of observed sea ice reduction events points in the same direction: Wang et al. (2009) find record lows of Arctic summer sea ice extent to be triggered by the DA pattern. Observations also show a shift from largely zonal AO SLP patterns over the Arctic towards more DA-like meridional circulation patterns after the millennium shift (Zhang et al., 2008). Concluding, decadal variability of the DA such as found in our model is a near-realistic feature, and thus our runs suggest the possibility of alternating intensity of ice loss events in the future.

Until recently, the only observed reference for our simulated RILEs was the 2007 sea ice record minimum event (e.g., Stroeve et al., 2008). As outlined in the introduction, atmospheric circulation anomalies dominated the event that was preconditioned by anomalously young and likely thin ice. The observed summer SLP pattern of below-normal pressure over Siberia and Laptev Sea and above-normal pressure over the western Beaufort Sea and northern Canada corresponds to the strongly meridional flow carrying heat from subpolar latitudes (Ogi et al., 2008). Dorn et al. (2012) emphasize the dependence of ice loss events on the atmospheric summer circulation. Those factors in modified shape are shown to play a vital role in the simulated events of our model, even if the polarity is different from the specific year 2007.

Kauker et al. (2009) find that winter preconditioning played a vital role for the 2007 event. We also find that reduced thickness already in winter can dominate the summer result. Reduced thickness can be preexisting, or it can be supported by winter atmospheric advection patterns.

The recent RILE in 2012 is not completely analyzed in all its components. First results by Devasthale et al. (2013) show that meteorological conditions during 2012 were not extreme, but preconditioning from winter through early summer may have played an important role. The marginal sea-ice zones along the central Eurasian and North Atlantic sectors remained warm throughout winter and early spring, supported by warm and humid air advection from the northeast Atlantic. Atmospheric circulation favored sea ice export during early summer, and warming over the Canadian Archipelago and southeast Beaufort Sea from May onward further contributed to accelerated sea-ice melt. 
All those observational studies relate rapid ice reduction to preconditioning and atmospheric circulation, which fits well with this papers message: preconditioned ice situations and atmospheric circulation anomalies play an important role for RILEs.

After the lowest sea ice extent is reached in an event in our scenario experiments, the following years show recovery of varying amplitude, characterized by a lack of the conditions mentioned above: winters are not much warmer than the respective 10-yr reference period, and anomalous atmospheric circulation shows only moderate meridional components. Ice thickness anomalies as created during the event do not predetermine a continued reduction of summer extent.

The fact that we do not see a complete sea ice removal down to almost zero before 2040 in our model could in principle be explained either by time limitation of supporting random winter and summer forcing conditions (which, coincidentally or forced by the large scale do not occur more than $1-3 \mathrm{yr}$ in a row) or by negative feedback mechanisms. A summer with little sea ice is always followed by a warm fall, and sea ice thickness anomalies can persist for several seasons. This gives a strong potential for another low-ice season the coming summer. That potential is used, e.g., in our simulated multi-step events, but it ceases mostly within 13 yr. Regular Arctic cooling mechanisms such as longwave upward radiation in combination with a less meridional atmospheric flow become the dominant influence. Reasons for a more zonal circulation after the events might be a response to the anomalously warm Arctic. A reduced meridional temperature gradient, connected to reduced cyclonic activity in subpolar regions, is suitable to reconstitute the large-scale dynamic isolation of the Arctic. From the existence of both multi-year events and single-year events in our experiments, we can conclude that no systematically dominating seasonal negative feedback exists in our model.

Recovery after ice reduction has been also seen regularly in the observed record of summer sea ice extent since 1979 (Stroeve et al., 2008). The ability of the sea ice to recover has also been demonstrated by Tietsche et al. (2011). A GCM is perturbed by complete removals of sea ice during summer. The response is a recovery back to the centennial trend due to compensating mechanisms such as increased heat loss at the top of the atmosphere and decreased heat gain by atmospheric advection from lower latitudes. Such seasonal negative responses or compensating mechanisms out-compete the positive feedbacks such as the sea ice albedo feedback.

Our model shows no specific role of sea ice export for rapid change events. Cases of most intense export rates are not related to strongest amplitudes of summer sea ice loss. Even compared to recent observed conditions, this is a plausible result: Stroeve et al. (2008) find that loss of old (multi-year) ice in the 1990s was accentuated by anomalous wind patterns that led to increased ice export through Fram Strait, while recent loss in the central Arctic is due to old ice failing to survive within the Arctic Ocean. Koenigk et al. (2006) found in a GCM-based study that Arctic sea ice volume is generally weakly correlated with export on interannual time scales.

Climate models have different deficiencies in describing sea ice processes. Despite problems, mechanisms are at work leading to interannual variability of sea ice conditions. The mechanisms for rapid ice loss we find here are predominantly related to seasonal-to-interannual memory buildup in the ice thickness, and due to atmospheric circulation.

An important role for atmospheric advection on ice conditions in the real world has been pointed out by Overland et al. (2008), who find atmospheric advective contributions to play an important role for SAT anomalies. Anomalous geostrophic winds for 2000-2007 often tended to blow toward the central Arctic, a meridional wind circulation pattern. In spring 2000-2005, these winds were from the Bering Sea toward the North Pole, whereas in 2006-2007 they were mostly from the eastern Barents Sea. A meridional pattern was also seen in the late 1930s with anomalous winter (DJFM) SAT, at Spitsbergen, of greater than $+4{ }^{\circ} \mathrm{C}$. Both periods suggest natural atmospheric advective contributions to the hot spots with regional loss of sea ice. Graversen et al. (2011) find, "in summer 2007 there was an anomalous atmospheric flow of warm and humid air into the region that suffered severe melt."

We also tested the idea of possible upward transport of ocean heat by vertical mixing in response to reduced ice concentration. Such a process was not found in this model, although observations indicate import of warm ocean water from the Pacific Ocean (Woodgate, 2010) and subsequent inclusion in vertical mixing. While those observed results are under discussion, we cannot expect to find them in the model due to coarse resolution and insufficient Bering Strait inflow.

Further observational studies indicate the possibility of contributions from temporarily and locally increased radiative effects (Francis and Hunter, 2006; Kay et al., 2008) or from black carbon aerosols (Shindell and Faluvegi, 2009). None of those effects plays a major role in our results. Instead we find RILEs triggered by atmospheric circulation anomalies, which kept going due to local anomalies of air temperature, ice thickness and bottom melting. In some cases we find find increased downward longwave radiation often in agreement with atmospheric advection from warmer areas. However, those are normally compensated by longwave upward radiation in the seasonal mean. In few cases we find a small net effect of longwave radiation on small remaining ice flows. This limited role of radiative effects does not contradict the observation-based result. Even in the real world, variability in the atmospheric circulation has played an especially prominent role for rapid ice loss (e.g., Serreze and Barrett, 2011), while radiative effects have been questioned (Schweiger et al., 2008).

RILEs in our model are evoked frequently without a major contribution initiated by the ocean or by radiative effects. Our model-based results illustrate the possibility of a 
prominent influence of atmospheric circulation variability. Thus, the mechanisms found in this paper should be seen as possible contributors to RILEs in a real world. They are most likely not the only contributors to real-world ice loss events. Enhanced roles for other mechanisms are well possible and need to be addressed in forthcoming studies.

In this paper we study a large number of events as average, as composites and as specific cases. Mostly, we are considering seasonal means. A follow-up study by Paquin et al. (2012) is focusing on specific RILEs with a partly increased role of radiative effects for certain months and certain cases.

Preconditioning and large-scale atmospheric circulation and conditions have been identified as a major cause to rapid change events in this study. Prediction efforts must thus focus on just those. A prediction system will have to rely on ice observations and atmospheric prediction. Local ice thickness as well as concentration will be essential. On the atmospheric side, seasonal prediction is subject of research, but will necessarily include elements of probability, which propagate to a seasonal ice forecast system. Lessons learned from the community S4D sea ice outlook effort (e.g., Kauker et al., 2009) are compatible with our finding on preconditioning during winter as an important element.

Acknowledgements. This work was carried out at the Rossby Centre at the Swedish Meteorological and Hydrological Institute (SMHI) and made possible by the support of the EU-DAMOCLES project and the ADSIMNOR project funded by the Swedish research council FORMAS. We further thank Ulf Hansson, Klaus Wyser and Markus Meier for contributing during the various phases of model development. We are also grateful to two anonymous reviewers who contributed with constructive questions and comments, which led to an improved paper.

Edited by: K. Dethloff

\section{References}

Alexander, M., Bhatt, U., Walsh, J., Timlin, M., Miller, J., and Scott, J.: The atmospheric response to realistic Arctic sea ice anomalies in an AGCM during winter, J. Clim., 17, 890-905, doi:10.1175/1520-0442(2004)017;0890:TARTRA $i 2.0 . C O ; 2$, 2004.

Blanchard-Wrigglesworth, E., Armour, K. C., Bitz, C. M., and DeWeaver, E.: Persistence and Inherent Predictability of Arctic Sea Ice in a GCM Ensemble and Observations, J. Clim., 24, 231250, doi:10.1175/2010JCLI3775.1, 2011.

Cassano, J. J., Higgins, M. E., and Seefeldt, M. W.: Performance of the Weather Research and Forecasting Model for MonthLong Pan-Arctic Simulations, Mon. Wea. Rev., 139, 3469-3488, doi:10.1175/MWR-D-10-05065.1, 2011.

Chapman, W. L. and Walsh, J. E.: Simulations of Arctic Temperature and Pressure by Global Coupled Models, J. Clim., 20, 609632, doi:10.1175/JCLI4026.1, 2007:
Comiso, J. C., Parkinson, C. L., Gersten, R., and Stock, L.: Accelerated decline in the Arctic sea ice cover, Geophys. Res. Lett., 35, L01703, doi:10.1029/2007GL031972, 2008.

Devasthale, A., Koenigk, T., Sedlar, J., and Fetzer, E. J.: The thermodynamic state of the Arctic atmosphere observed by AIRS: comparisons during the record minimum sea-ice extents of 2007 and 2012, Atmos. Chem. Phys. Discuss., 13, 177-199, doi:10.5194/acpd-13-177-2013, 2013.

Dorn, W. , Dethloff, K., Rinke, A., and Kurgansky, M.: The recent decline of the Arctic summer sea-ice cover in the context of internal climate variability, The Open Atmospheric Science Journal, 2, 91-100, doi:10.2174/1874282300802010091, 2008.

Dorn, W., Dethloff, K., and Rinke, A.: Limitations of a coupled regional climate model in the reproduction of the observed Arctic sea-ice retreat, The Cryosphere, 6 , 985-998, doi:10.5194/tc-6985-2012, 2012.

Döscher, R., Willen, U., Jones, C., Rutgersson, A., Meier, H. E. M., and Hansson, U.: The development of the coupled oceanatmosphere model RCAO, Boreal. Environ. Res., 7, 183-192, 2002.

Döscher, R., Wyser, K., Meier, H., Qian, M., and Redler, R.: Quantifying Arctic Contributions to Climate Predictability in a Regional Coupled Ocean-Ice-Atmosphere Model, Clim. Dynam., 34, 1157-1176, doi:10.1007/s00382-009-0567-y, 2010.

Francis, J. A. and Hunter, E.: New Insight Into the Disappearing Arctic Sea Ice, Eos Trans. AGU, 87, 509-511, doi:10.1029/2006EO460001, 2006.

Gerdes, R. and Köberle, C.: Comparison of Arctic sea ice thickness variability in IPCC Climate of the 20th Century experiments and in ocean - sea ice hindcasts, J. Geophys. Res., 112, C04S13, doi:10.1029/2006jc003616, 2007.

Graversen, R. G., Mauritsen, T., Drijfhout, S., Tjernström, M., and Mårtensson, S.: Warm winds from the Pacific caused extensive Arctic sea-ice melt in summer 2007, Clim. Dyn., 36, 2103-2112, doi:10.1007/s00382-010-0809-z, 2010.

Holland, M. M., Bitz, C. M., and Tremblay, B.: Future abrupt reductions in the summer Arctic sea ice, Geophys. Res. Lett., 33, L23503, doi:10.1029/2006GL028024, 2006.

Hunke, E. C. and Dukowicz, J. K.: An elastic-viscous-plastic model for sea ice dynamics, J. Phys. Oceanogr., 27, 1849-1867, doi:10.1175/1520-0485(1997)027;1849:AEVPMF i2.0.CO;2, 1997.

IPCC: Climate Change 2007 - Impacts, Adaptation and Vulnerability Contribution of Working Group II to the Fourth Assessment Report of the IPCC (978 0521 88010-7 Hardback; 9780521 70597-4 Paperback), 2007.

Jones, C. G., Willén, U., Ullerstig, A., and Hansson, U.: The Rossby Centre Regional Atmospheric Climate Model - Part 1: model climatology and performance for the present climate over Europe, Ambio, 33, 199-210, 2004a.

Jones, C. G., Wyser, K., Ullerstig, A., and Willén, U.: The Rossby Centre Regional Atmospheric Climate model - Part 2: application to the Arctic climate, Ambio, 33, 211-220, 2004b.

Kauker, F., Kaminski, T., Karcher, M., Giering, R., Gerdes, R., and Voßbeck, M.: Adjoint analysis of the 2007 all time Arctic sea-ice minimum, Geophys. Res. Lett., 36, L03707, doi:10.1029/2008GL036323, 2009.

Kay, J. E., L'Ecuyer, T., Gettelman, A., Stephens, G., and O’Dell, C.: The contribution of cloud and radiation anomalies to the 2007 
Arctic sea ice extent minimum, Geophys. Res. Lett., 35, L08503, doi:10.1029/2008GL033451, 2008.

Kjellström, E., Bärring, L., Gollvik, S., Hansson, U., Jones, C., Samuelsson, P., Rummukainen, M., Ullerstig, A., Willén, U., and Wyser, K.: A 140-year simulation of European climate with the new version of the Rossby Centre regional atmospheric climate model (RCA3), SMHI reports meteorology and climatology RMK, 108, 54 pp., 2005.

Koenigk, T., Mikolajewicz, U., Haak, H., and Jungclaus, J.: Variability of Fram Strait sea ice export: causes, impacts and feedbacks in a coupled climate model, Clim. Dyn., 26, 17-34, 2006.

Koenigk, T., Döscher, R., and Nikulin, G.: Arctic future scenario experiments with a coupled regional climate model, Tellus A, 63, 69-86, doi:10.1111/j.1600-0870.2010.00474.x, 2011.

Køltzow, M.: The effect of a new snow and sea ice albedo scheme on regional climate model simulations, J. Geophys. Res., 112, D07110, doi:10.1029/2006JD007693, 2007.

Kwok, R.: Summer sea ice motion from the $18 \mathrm{GHz}$ channel of AMSR-E and the exchange of sea ice between the Pacific and Atlantic sectors, Geophys. Res. Lett., 35, L03504, doi:10.1029/2007GL032692, 2008

L'Heureux, M. L., Kumar, A., Bell, G. D., Halpert, M. S., and Higgins, R. W.: Role of the Pacific-North American (PNA) pattern in the 2007 Arctic sea ice decline, Geophys. Res. Lett., 35, L20701, doi:10.1029/2008GL035205, 2008.

Maslanik, J. A., Fowler, C., Stroeve, J., Drobot, S., Zwally, H. J., Yi, D., and Emery, W. J.: A younger, thinner Arctic ice cover: Increased potential for rapid, extensive sea ice loss, Geophys. Res. Lett., 34, L24501, doi:10.1029/2007GL032043, 2007.

Massonnet, F., Fichefet, T., Goosse, H., Bitz, C. M., PhilipponBerthier, G., Holland, M. M., and Barriat, P.-Y.: Constraining projections of summer Arctic sea ice, The Cryosphere Discuss., 6, 2931-2959, doi:10.5194/tcd-6-2931-2012, 2012.

Mårtensson, S., Meier, H. E. M., Pemberton, P., and Haapala, J.: Ridged sea ice characteristics in the Arctic from a coupled multicategory sea ice model, J. Geophys. Res., 117, C00D15, doi:10.1029/2010JC006936, 2012.

Meier, H. E. M., Döscher, R., and Faxén, T.: A multiprocessor coupled ice-ocean model for the Baltic Sea: application to salt inflow, J. Geophys. Res., 108, 3273, doi:10.1029/2000JC000521, 2003

Ogi, M., Rigor, I. G., McPhee, M. G., and Wallace, J. M.: Summer retreat of Arctic sea ice: Role of summer winds, Geophys. Res. Lett., 35, L24701, doi:10.1029/2008GL035672, 2008.

Overland, J. E. and Wang, M.: Large-scale atmospheric circulation changes are associated with the recent loss of Arctic sea ice, Tellus A, 62, 1-9, doi:10.1111/j.1600-0870.2009.00421.x, 2010.

Overland, J. E., Wang, M., and Salo, S.: The recent Arctic warm period, Tellus A, 60, 589-597, doi:10.1111/j.16000870.2008.00327.x, 2008.

Paquin, J.-P., Paquin, R., Döscher, L., Sushama, T., and Königk, T.: Causes and consequences of mid-21st Century Rapid Ice Loss Events simulated by the Rossby Centre Regional AtmosphereOcean model, submitted, 2013.

Perovich, D. K., Richter-Menge, J. A., Jones, K. F., and Light, B.: Sunlight, water, and ice, Extreme Arctic sea ice melt during the summer of 2007, Geophys. Res. Lett., 35, L11501, doi:10.1029/2008GL034007, 2008.
Redler, R., Valcke, S., and Ritzdorf, H.: OASIS4-a coupling software for next generation earth system modelling, Geosci. Model Develop., 3, 87-104, 2010.

Samuelsson, P., Gollvik, S., and Ullerstig, A.: The land-surface scheme of the Rossby Centre regional atmospheric climate model (RCA3), Report in meteorology 122, SMHI, SE-601 76 Norrköping, Sweden, 2006.

Schweiger, A. J., Zhang, J., Lindsay, R. W., and Steele, M.: Did unusually sunny skies help drive the record sea ice minimum of (2007, Geophys. Res. Lett., 35, L10503, doi:10.1029/2008GL033463, 2008

Semtner, A. J.: A model for the thermodynamic growth of sea ice in numerical investigations of climate, J. Phys. Oceanogr., 6, 27-37, 1976.

Serreze, M., Andrew, C., and Barrett, P.: Characteristics of the Beaufort Sea High, J. Climate, 24, 159-182, doi:10.1175/2010JCLI3636.1, 2011.

Shindell, D. and G. Faluvegi: Climate response to regional radiative forcing during the twentieth century, Nature Geosci., 2, 294-300, doi:10.1038/ngeo473, 2009

Steele, M., Rebecca, M., and Wendy, E.: PHC: A Global Ocean Hydrography with a High-Quality Arctic Ocean, J. Climate, 14, 2079-2087. doi:10.1175/1520 0442(2001)014;2079:PAGOHW i2.0.CO;2, 2001

Stroeve, J., Serreze, M., Drobot, S., Gearhead, S., Holland, M., Maslanik, J., Meier, W., and Scambos, T.: Arctic sea ice extent plummets in 2007, Eos, Trans. Amer. Geophys. Union, 89, 13 14, 2008.

Tietsche, S., Notz, D., Jungclaus, J. H., and Marotzke, J.: Recovery mechanisms of Arctic summer sea ice, Geophys. Res. Lett. 38, L02707, doi:10.1029/2010GL045698, 2011.

Vancoppenolle, M., Fichefet, T., Goosse, H., Bouillon,S., König Beatty, C., and Morales Maqueda, M. A.: LIM3, an advanced sea-ice model for climate simulation and operational oceanography, Mercator Ocean Quarterly Newsletter, 28, 16-21., 2008.

Walter, K., Ute L., and Klaus F.: A Response Climatology of Idealized Midlatitude Thermal Forcing Experiments with and without a Storm Track, J. Clim., 14, 467-484, doi:10.1175/15200442(2001)014;0467:ARCOIM $i 2.0 . C O ; 2,2001$.

Wang, J., Zhang, J., Watanabe, E., Ikeda, M., Mizobata, K., Walsh, J. E., Bai, X., and Wu, B.: Is the dipole anomaly a major driver to record lows in Arctic summer sea ice extent?, Geophys. Res. Lett., 36, L05706, doi:10.1029/2008GL036706, 2009.

Woodgate, R. A., Weingartner, T., and Lindsay, R.: The 2007 Bering Strait Oceanic Heat Flux and anomalous Arctic Sea-ice Retreat, Geophys. Res. Lett., 37, L01602, doi:10.1029/2009GL041621, 2010.

Wu, B., Wang, J., and Walsh, J. E.: Dipole Anomaly in the Winter Arctic Atmosphere and Its Association with Sea Ice Motion, J. Clim., 19, 210-225, 2006.

Zhang, X. and Walsh, J. E.: Towards a seasonally ice-covered Arctic Ocean: Scenarios from the IPCC AR4 simulations, J. Clim., 19, 1730-1747, 2006.

Zhang, X., Sorteberg, A., Zhang, J., Gerdes, R., and Comiso, J. C.: Recent radical shifts of atmospheric circulations and rapid changes in Arctic climate system, Geophys. Res. Lett., 35, L22701, doi:10.1029/2008GL035607, 2008. 